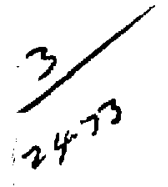

$33^{4 y^{4}}$

DR 232

\title{
ELEMENTAL ANALYSIS OF AIR FILTER SAMPLES USING X-RAY FLUORESCENCE
}

UCRL-51388

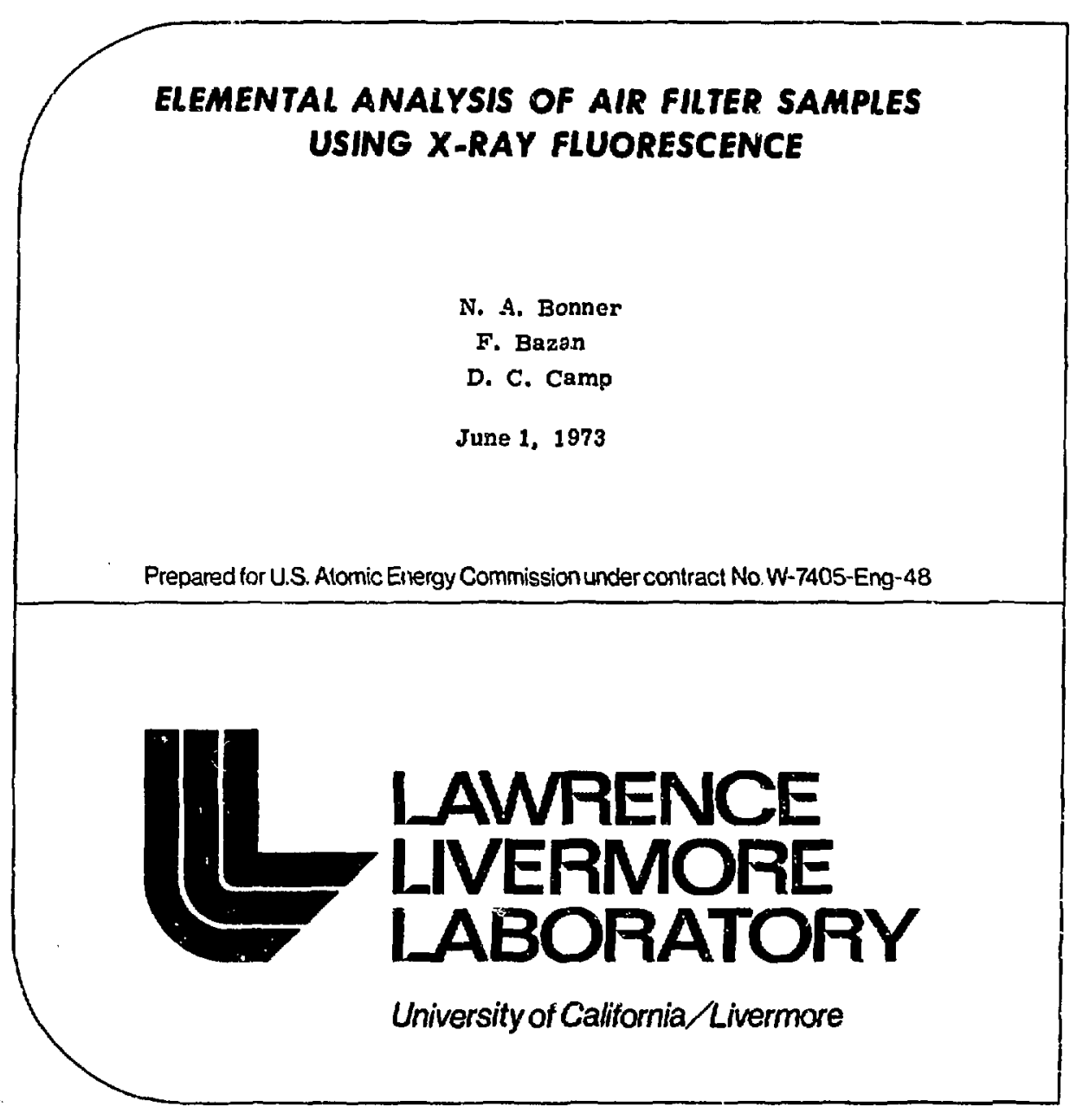

MASTER

DISTREUTION OF THIS DOCURENT IS UNLIMITES 
NOTKE:

"Thin teport was presued at an account of woth sponorad by

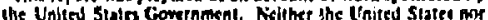

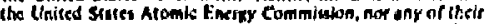
empioyecs, mor any cl theis conlfacton, nubecinlescfort, or thete



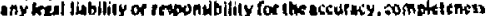

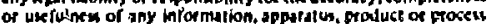

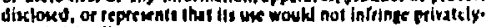
owned plifts."

Printed in the United States of America Available from

National Technical Information Service

U.S. Department of Commerce 5285 Port Royal Road

Springfield, Virginia 22151

Price: Printed Copy $\$$ _ Microfiche $\$ 0.95$

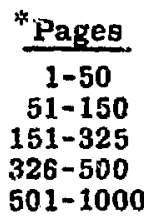

NTIS

Selling Price 
TID-4500, UC-4

Chemlstry

\title{
노 \\ LANAENCE LNEGMORE LAEOAATOPY

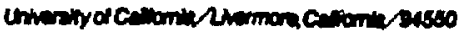

\section{UCAL-51398 \\ ELEMENTAL ANALYSIS OF AIR FILTER SAMPLES USING X-RAY FLUORESCENCE}

\author{
N. A. Bonner \\ F. Bazan \\ D. C. Camp
}

MS. date: June 1, 1973

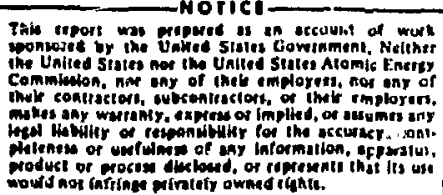

Twh orfort wo waperes is in eccululs of work

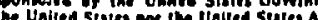

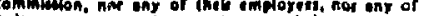

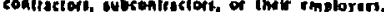

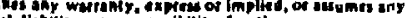

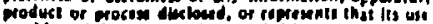

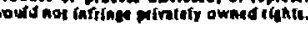

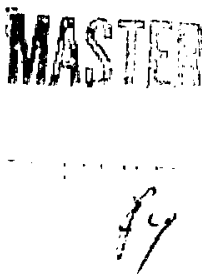




\section{Contents}

Abstract . . . . . . . . . . . . . . . 1

Summary of Purpoeses of Contract and Results Oblained . . . . . . I

Statement of Work . . . . . . . . . . . . . . . 2

Elemental Analysis of Air Filter Samples Using X-ray Fluorescence . 2

System Design and Operation . . . . . . . . . . . . . . 3

Description of System and Principles of Operation . . . . . 3

The Detector . . . . . . . . . . . . . 3

The Excitor . . . . . . . . . . . . . . 4

System Geounetry . . . . . . . . . . . . . . . 5

Data Mandling . . . . . . . . . . . . . . 8

Electronies and Computer Display $\quad$. $\quad . \quad$. . . . . . . 9

Detz Reduction . . . . . . . . . . . . . 11

Callbration . . . . . . . . . . . . . . . . 18

Callbration Procedures . . . . . . . . . . . . 18

Sensitivilies . . . . . . . . . . . . . 20

Detectabiltties . . . . , . . . . . . . . 22

Absorption Corrections for Hivol Samples . . . . . . . . 23

Experimental Results . . . . . . . . . . . . . 27

Accuracy . . . . . . . . . . . . . . . 27

Reproduclbillty of Measurements . . . . . . . . . 30

Some Characteristics of HiVol Samplea $\quad . \quad$. . . . . . . . 31

Bay Area Air Pollution Control District Samples . . . . . . 32

Suggested Improvements for Future Syatems . . . . . . . . . 33

Modification of the Present Deslgn . . . . . . . . . 33

Other Methods of X-ray Excitation . . . . . . . . . 35

Peripheral Equipment Improvement . . . . . . . . . 38

Commercial Equipment . . . . . . . . . . . 36

Summary and Conclusions $\quad$. . . . . . . . . . . . . 37

References . . . . . . . . . . . . . . . 38

Appendix A . . . . . . . . . . . . . . . . . 39

Detalled Description of Electronics System and Costs . . . . 32

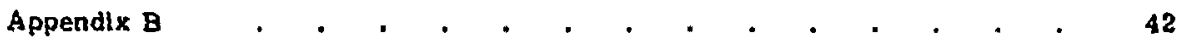

$X$-ray Absorption Corrections . . . . . . . . . . . . 42

Appendix C C . . . . . . . . . . . . . . . 47

Estimated Cost Per Sample . . . . . . . . . . . . 47 


\section{ELEMENTAL ANALYSIS OF AIR FILTER SAMPLES USING X-RAY FLUORESCENCE *}

\section{Abstract}

An x-ray nuorescence system has been clesigned to make elemental analyses of air fliter samples. It consists of radiolsotope excitera, a $S i(L i)$ detector and a computer based pulse helght analyzar.

It le capable of making qualitative measuremests of all elements heavier than phoaphorus $(Z=15)$ and quantitative measurements of all elements heavier than potassium $(Z=19)$. For samples on Whatman $41^{\dagger}$ filter paper and nuoresced for $1000 \mathrm{sec}$, the three sigma detection limits range from 10 to $100 \mathrm{ng} / \mathrm{cm}^{2}$.
These correspond 1,03 to $30 \mathrm{ng} / \mathrm{m}^{3}$ of air for typical 24-kr collections with Hivol samplers.

Accuracy of the system is within $\pm 10 \%$ and reproducibility 18 better than $5 \%$.

The method requires no sample preparation and is completely nondestructive.

Quantltalive Information obtalned with such a system can be useful in monitoring trace element concentrations in air, hence in providing data for the formulation and enforcement of air quality standards.

\section{Summary of Purpose of Contract and Results Obtained}

The purpose of the contract was to establish the design of an $x$-ray fluorescence system to determin the elemental composition of alrborne particulate matter as outlined in "Statement of Work" below, We have assembled such a system, cellbrated it and tested Its capabilities and limitations on air fulter samples to demonstrate the design principles.
The system can measure quantitatively all elements heavier tinan chlorine on a sample collected on a clean, low atomic number materlal (Whatman 41 paper, for example). The lirsits of detectability vary with atomic number and running time, but typlcally $30 \mathrm{ng} / \mathrm{cm}^{2}$ can be detected or a filter sample. This corresponds to about $10 \mathrm{ng} / \mathrm{m}^{3}$ for a 24 hr HiVol sample. A complete

\footnotetext{
*Work undertaken pursuant to California Air Resources Board (ARB) agreement No. ARB 037, April 1, 1972 and ARB proposal No, 3-042-1.

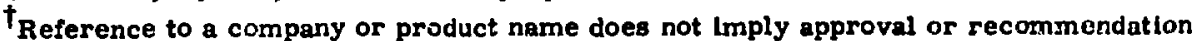
of the product by the University of Callfornis or the U.S. Atomic Energy Commisaion to the excluaion of others wat may be aultable.
} 
analysis requires about $30 \mathrm{~min}$ per sample.

A system similar to this one would appear to be extremely useful for monitoring particulate air contaminants. Thousands of air filter samples are collected each year in California, but only a few are analyzed for more than total weight of particulate matter collected.
An automated $x$-ray system would allow the analysis of a large fraction of the samples for many elements, thus giving a much more complete piciure of the nature of air pollutants throughout the State. Quantitative information of this type is vitally necessary if air pcllution regulations are to be formulated and enforced in a reasonable and effective way.

\section{Statement of Work}

ELEMENTAL ANALYSIS OF AIR FILTER SAM PLES USING $X-R A Y$ FI,UORESCENCE:

The Princlpa! Investigator shall within fourteen (14) months from the date of project initiation provide the necessary personnel, facilities, materials and supplies to establish the design of an $x$-ray fluorescence system and to demonstrate and report on its capability for determining the elemental composition of samples of airborne particulate matter.

Specific tasks to be accomplished shall consist of the following:

(1) Design, construct and Integrate into an operational system a radiation source, radiation shlelding, beam collimator, sample holder, necessary detection and inalytical equipment, and data recording equipment necessary to permit rapid analysis of airborne particulate matter samples.

(2) Experimentally evaluate the aystem design and establish its operational capability and sensitivity. Thts

\footnotetext{
Revised 6/25/71.
}

will be done by the analysis of a suffictent number of samples of selected filter media to insure the validity of the results using tir ie filter media. The Principal Investigator will select filter media to optimize compatibility with $x$-ray fuorescence analysis.

(3) Prepare and submit to the Air Resources Board's Technical Monitor informal monthly reports. Prepare and submit a draft of the final report to the Air Resources Board's Technical Monitor for review and approval. Submit the final report fourteen (14) months after project initiation. The final report shall lnclude: Details of the engineering design; aystems operating procedures; sample collection and mounting procedures; report of the evaluation conducted under Tusk ( $a$ ! above; analytical capabilities of the system, including a matrix of dotectable elements, associated sensitivity and standard deviation; and an estimate of equipment cost and operational cost on a per sample basis. 


\section{System Design and Operation}

$\mathrm{X}$-ray fluorescence is a technique well suited to the routine analysis of air fliter samples. An ideal analytlcal system would cover a wide range of elemerts, be fast, accurate, simple to operate, non-destructive and at least reasonably small, if not portable.

The system we have assembled meets many of these requirements:

1) It covers a wide range of elements.

2) It requires about $30 \mathrm{~min}$ for a complete analysis.

3) It is completely non-deatructive to air filter samples.

4) The system occupies about $12 \mathrm{ft}^{2}$ of floor space and could be made portable.

\section{DESCRIPTION OF SYSTEM AND PRINCIPLE OF OPERATION}

The principle of $x$-ray analys is is extremely simple. Each element, when properly excited, emits characteristic $x$ rays. Identification is strqightforward because the energies of the $x$ rays emitted by each element are unique and well known. Appropriate calibration of the instruments used allow quantitative measurement of the amount of each elemient present as well as identification of the elements.

There are two basic components necessary for any $x$-ray analysis system - a method for exciting $x$-ray emission, and a detector system which is capable of measuring $x$-ray energies and intensitles. Figure 1 shows a sketch of the essential components. The physical arrangement of sample, detector and exciter is similar to a system first described by
Giauque.' In addition, varlous kinds of electronic instrumentation are needed for processing, sorting and storing the signals produced in the detector by $x$ rays.

The following se:tions will discuss each purt of the $x$-ray fuorescence andlyzer in more detall.

\section{THE, DETECTOR}

The detector used in our system is a solid state lithium-drifted silicon crystal, ablirevlated $\mathrm{Si}(\mathrm{Li})$. Its great advantage is that it is an energy sensitive device (i.e. the slze of the ignal pulse is proportional to the energy of the detected $x$ ray). Thus, $x$ rays from different elements produce signals witch can be sorted and stored electronically.

This non-dispersive energy sensitivity ultimately results in much faster data analysis than systems which require

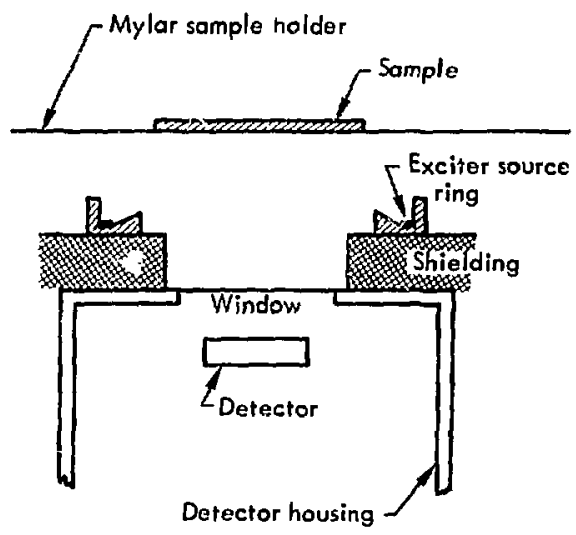

Fig. 1. Simplified sketch shorring the relative positions of sample, detector, exciter source and shielding. 
-hat the $\mathrm{x}$ rays be sorted accoraing to wavelength and measured separately. The Si(Li) detector msasures the entire spectrum of incident $x$ rays during one counting interval.

The energy resolution of our Si(Li) detector is adequate to separate the $x$ rays from adjacent elemento for all elements above sodium $(Z=i j)$. Since phosphorus $Z=15$ is the lightest element we measure, this resolution is adequate for our purposes.

\section{THE EXCITER}

$X$-rays can be excited by various neass. The most common methods used to obtain analytical results are irradtation by photoris, protons or alpha particles. The question of which method provides the greatest sensitivity for trace element analysis is not easily answered because there are many variables which must be considered. At least several more years will be required before any clear cholce becomes evident. Certainly $x$-ray excitation by radioactive source photons is simple, reliable, and requires only a small amount of equipment and floor space.

Our system employs three sadibactive sources as exciters. Thiee are neces-ary because no single exciting energy ian provide adequate sensitivity over the entice range of trace elements. An ideal radioactive source would have a long half-life and errit photons of a single energy. There are only a few radioactive isotopes available with the proper characteristics. From a practical stariipoint we have found that the most useful source is ${ }^{109} \mathrm{Cd}$. It has a 453 day half-life, and decays by electron cepture to stable ${ }^{109} \mathrm{Ag}$. The principal radiations emitted are the silver $K_{a}$ and $K_{\beta} \times$ rays with energies of 22.1 and $25.0 \mathrm{keV}$. There is also an $88 \mathrm{keV}$ gamma ray but its abundance is low, about 3\%. Thus, there are no high energy gamma rays to cause Compton events in the detector, and no high energy betas to produce a bremsstrahlung continuum. The two silver $x$ rays are well sulted to exclte the $K \times$ rays of the first row transition elements and the $L$ $x$ rays of heavy elements such as lead. These are two of the more interesting regions of the periodic table with regard to trace elements in envisonmental samples.

The ${ }^{109} \mathrm{Cd}$ source was prepared by plating it onto a sllver ring, gluing the ring into a sllver holder, then covering the source with enough pure aluminum to absorb counpletely the conversion electrons and Auger electrons fa hickness of 0.005 in. is adequate). The aluminum aboorber is glued in place with epoxy and serves as a container for the oource, preventing leakage and contamination.

A serond source is ${ }^{55} \mathrm{Fe}$, It has a 2.7 year half-lise and emits 5.9 and 6.5-keV Mn x rays, which are useful for exciting the elements between phosphorus and vanadium. it is prepared by plating the iron onto a copper ring, putting the ring into a tungsten holder, and covering the source with 0,002 in. Be.

The third source we have used is 241 Am, with a 458 year half-life. It emits a 59.4-keV gamma ray which is usefui for the intermediate elements from ruthenium to the middle of the rare 
earths. Unfortunately, it also emits $\mathrm{Np}$ $L x$ rays in the energy range 13 to $21 \mathrm{keV}$, and two low intensity gamma rays at 26 and $33 \mathrm{k \in V}$. We have used it to measure sensitivities in the intermediate range, but the spectrum is so complicated that it is difficult to use routinely. It should be possible to prepare an appropriately shielded source which emits essentially pure $59.4-\mathrm{keV}$ radlation, but we had neither time nor funds to do it. The Am source we have used was prepared by putting $\mathrm{Am}_{2} \mathrm{O}_{3}$ into a doughnut-shaped aluminum tube, sealing the tube, then gluing it into a tungsten source ring holder and gluing an aluminum absorber over the tube.

The radiation safety aspects associaied with the handling and use of these $x$-ray fluorescent sources should include:

1. Proper licensing of sources with USAEC.

2. Adequate storage facilities, preferably a lockable lead container offering adequate attenuation.

3. Enough physical separation between source position and any personnel to reduce exposure levels below $0.25 \mathrm{mr} / \mathrm{hr}$.

4. Periodic monitoring of general work area with an approprlate survey instrument, e.g. Victoreen Model 440 or Technical Associate Model 6, 7, or 8 .

5. A swipe test should be taken monthly to ensure structural integrity of sources.

\section{SYSTEM GEOMETRY}

The primary source of background counts in the detector is exciter radia.. tion scattred into the detector by the sample. One of the major scattering processes is Compton scattering, which has a minimum intensity at $10^{\circ}$. Thus, there is a minimum in the background when the detector line of sight is at $90^{\circ}$ with respect to the path of the source radiation. Unfortunately, a $90^{\circ}$ geometry complicates the shielding requirements, leading to large separations between sample and detector and between sample and exciter. The exciter source strength is so high that there must be no direct line-of-sight path from the source to the detector. Furthermore, the only single or multiple scatter paths allowable are those caused unavoidably by the sample itgelf.

For maximum sensitivity the distances from exciter to sample and from sample to detector should be as small as possible. The use of $180^{\circ}$ geometry combined with high dens ity tungsten alloy shielding allows the minimum separations consistent with adequate shielding.

The overall system geometry is shown in Fig. 2. Figure 3 is a more detailed view showing the relative positions of the exciter, the detector and the sample.

Since there is no "best" diameter of the exciter, we chose one large enough to more or less uniformly illuminate the area directly over the detector.

To optimize the sample position, we made a series of measurements with a variety of spacer rings under the sample holder. These rings are used to set the distance of the sample holder above the source and detector. For each spacer we measured the signal from a small $(\sim 1 \mathrm{~mm}$ diameter) piece of an appropriate 


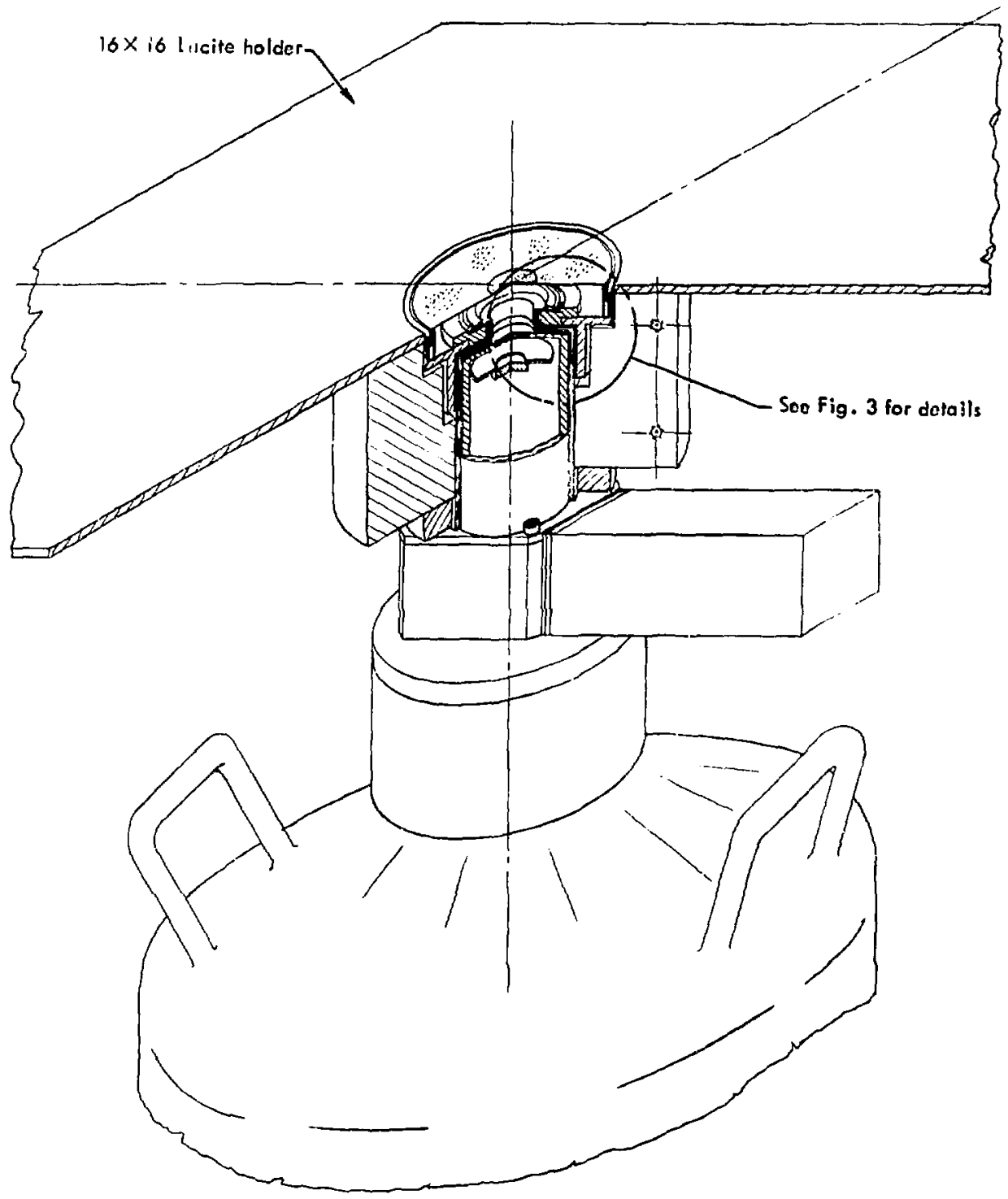

Fig. 2. Perspective drawing of the detector, exciter and sample holder. 


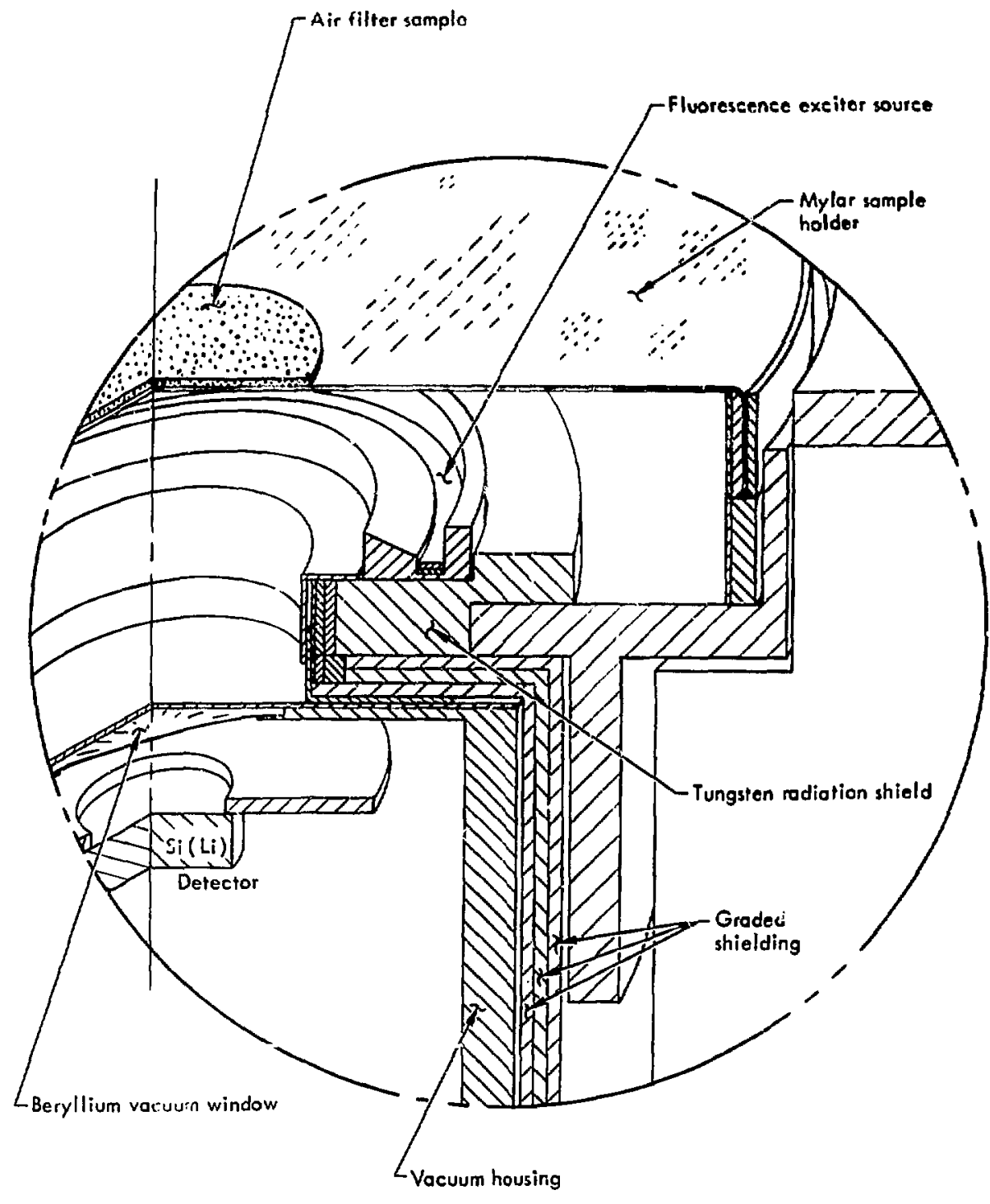

Fig. 3. Expanded perspective drawing showing the details of the exciter, sample holder, detector and shielding. 
element placed at differcnt distances from the center of the sample holder. Figure 4 shows the results of several such series of mensurements using a Zr sample with the ${ }^{100} \mathrm{Cd}$ source. We chose the $1 / 4$ in. spacer for our final design. This spacing pives a nearly constant response from the center out to a diameter of nearly 0.9 in.; beyond this diameter the response falls off extremely rapidly. The system thus gives a nearly uniform responge to the trace elements present within a fairly well defined area of about $1 \mathrm{ln}$. diam.

Stileiding the detector from dircet exciter radiation is fairly simple. The most penetrating radiation in any of our sourcee is the $88-k e V$ gamma ray from the ${ }^{109} \mathrm{Cd}$ source. $A$ t/O in. thickness 0 i tungsten will attenuate this by a morethan-adequate factor of about $10^{10}$.

More difficult is the elimination of multiply-scattered radiation and impurity peaks from construction materials. The rather complicated arrangement of graded shields scen in the final design is necessary in order to remove these

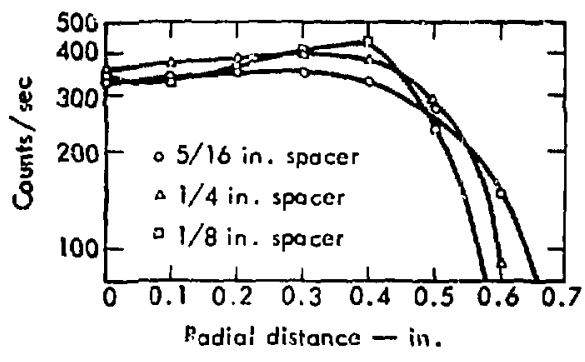

Fig. 4, Response vs. distance from center as a function of height of sample holder. These data were obtained using a $109 \mathrm{Cd}$ source with a $1 \mathrm{~mm} \times 1 \mathrm{~mm} \mathrm{Zr}$ sample. two sources of background and interrerences.

The exciter sourses used are extremely intense in terms of the counting rates normally encountered by the detector. A fairly strong detector signai for a single element is about one count per Bccond (cps), while the source disinteyration rates are greater than $10^{8} / \mathrm{sec}$. This means that even very unlikely paths can lead to signals in the det yctor. Consider, for example, tho $\mathrm{Pb}-\mathrm{Cd}-\mathrm{Cu}$ shleld extending down the neck of the Dewar housing the detector. This shlolding is necessary oven ttough all paths to the detector through the lower housing require source radiation to be scattered at least twice.

Impurlty peaks arise because of the cxtreme sonsitivity of the system. (Without any sample holder or sample, the 1.14 prm by volume of krypton in alr can be secn in an overnight nuoregcenco.) It is very difficult to remove the last microgram of all detcctable clements from arcas or surfoces irradiated. As an example of this problem, at one point early in the development, we found a Pb peak of unknown origln. We ninally traced it to a small amount of $\mathrm{Pb}$ in the paint used on the wall next to the instrument. Fortunately this was an easy one to eliminate - we merely moved the assembly away from the wall. Most of the other impurity peaks were eliminated by the appropriate positioning of graded shtelding.

The use of silver as the source holder for the ${ }^{109} \mathrm{Cd}$ source is the result of our attempts to make the system as clean as possible. Our crigiral ${ }^{109} \mathrm{Cd}$ source 
wos plated on copper and mourted in tungsten. This arranzement led to complleated shlelding of the source it self to remove copper and other peaks from the tungsten alloy. Since the $\mathrm{Cd}$ source emits sllver $x$ rays, there is no way for the silver holder to interfere with the cleanliness of the spectrum unless it contains impurities. Fortunately ordinary allveg ts pure ensugh for our purposes.

If the system were to be redesigned, the shtelding construction could be simplified somewhat, but the essentials of the graded shiclic would have to be retained. Grading makes a thinner shield; an ungraded shleld would have to be made of the lightest element in the set.

\section{Data Handling}

\section{ELECTRONICS AND COMPUTER DISPLAY}

The signals produced by $x$ rays in the Si(Li) detector are processed as shown in the simplifled block diagram of Fig. 5. (Appendix A describes the electro:ics systein in more detail.)

The pulses from the preamplifier are routed to a linear amplifier and pile-up rejection circuit. The latter circuit eliminates interference between pulses that follow one another so closely that neither can be hanuled properly. It also corrects for the system "dead time," 1.e., the time spent processing pulses.

Next the analog to digital convexter receives pulses from the linear amplifier and converts them to signals compatible with a digital computer.

The computer keeps track of the number of pulses which occur in each energy interval. It can then be programmed to display the data, plot it on an $\mathrm{X}-\mathrm{Y}$ plotter, print it on a teletype or record it on magnetic tape. The computer can also bi programmed to perform mathematcal operations on the data.

We usually display the data as a spectrum with the $x$ axis corresponding to energy and the $y$ axis corresponding to the number of pulses in each energy interval. Figurc 6 is a plot of such a spectrum obtained with the ${ }^{109} \mathrm{Cd}$ exclter with no sample and with the sample holder removed.

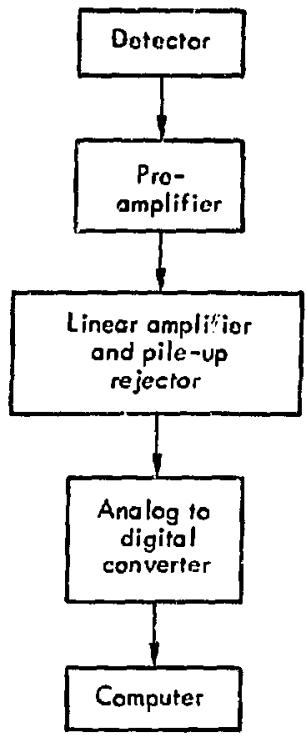

Fig. 5. Simplified block cilagram of pulse height analys is electronics. 


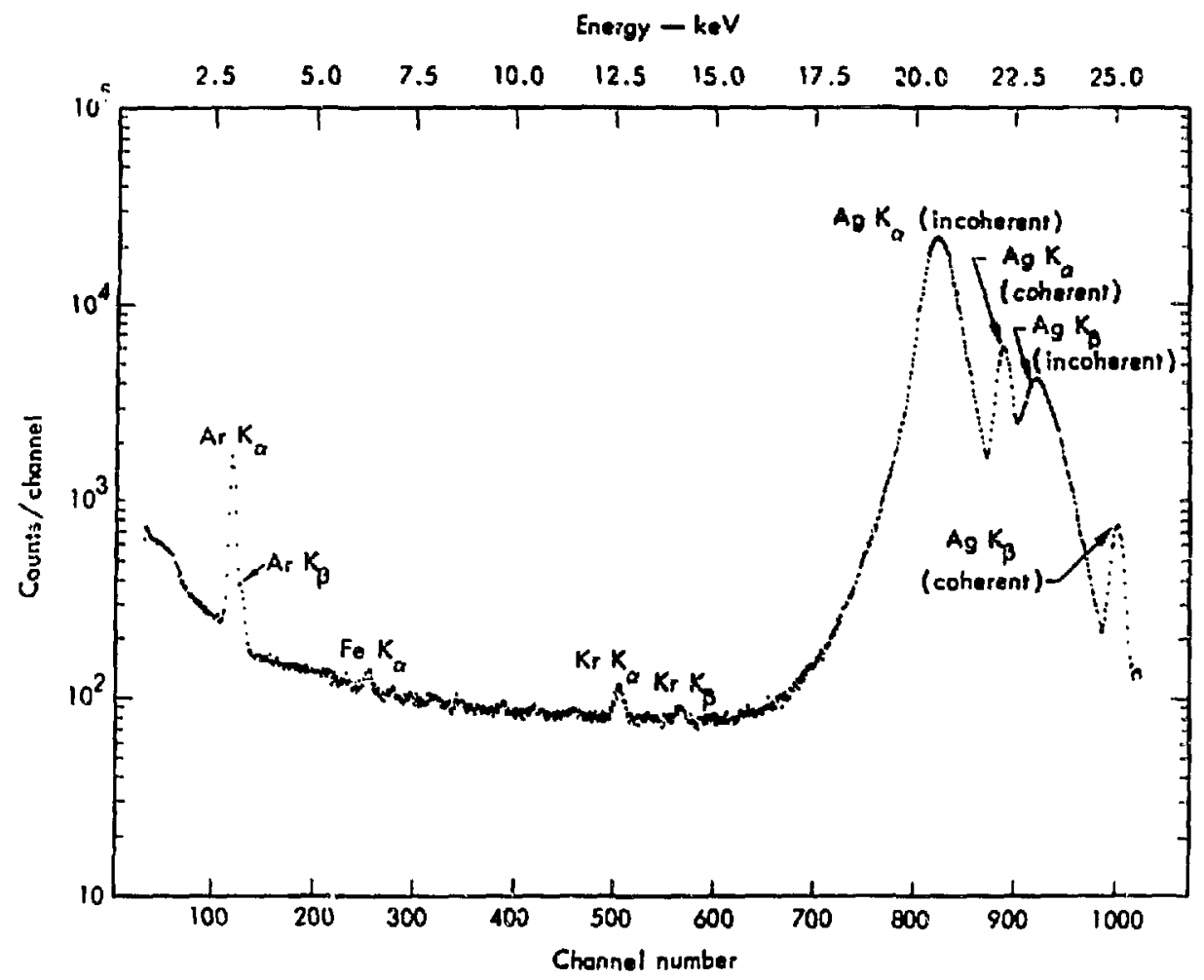

Fig. 6. A spectrum with the ${ }^{109} \mathrm{Cd}$ exciter. This is a $50 \mathrm{ksec}$ count with no sample, and with the sample holder removed. The major features of the spectrum are identified. The only visible impurity peak from the system itself is the Fe $K_{\alpha} \times$ ray.

The four large peaks on the right are characteristlc of the source. The peaks at 22.1 and $25.0 \mathrm{keV}$ are the coherently scattered $\mathrm{Ag} \mathrm{K}_{\alpha}$ and $\mathrm{K}_{\beta} \times$ rays. The broader peaks at about 20.6 and $23.0 \mathrm{keV}$ are the result of Compton (incoherent) scattering of the two $x$ rays. These peaks are shifted down in energy because a Compton-scattered photon loses energy to the electron which acatters it.

Figure 6 also shows the intrinsic cleanliness of the system. This was an overnight count in which the only visible Impurity peak is iron (Fc) at $6.4 \mathrm{keV}$. The $A r$ and $K r$ peaks are from the air and could be eliminated by removing the air.

Figures 7 and $B$ show spectra taken with the ${ }^{55} \mathrm{Fe}$ and ${ }^{241} \mathrm{Am}$ exciters, respectively. The complexlty of the ${ }^{241}$ Am spectrum below $27 \mathrm{keV}$ makes it clear why this source is less useful than the ${ }^{109} \mathrm{Cd}$ exciter. 


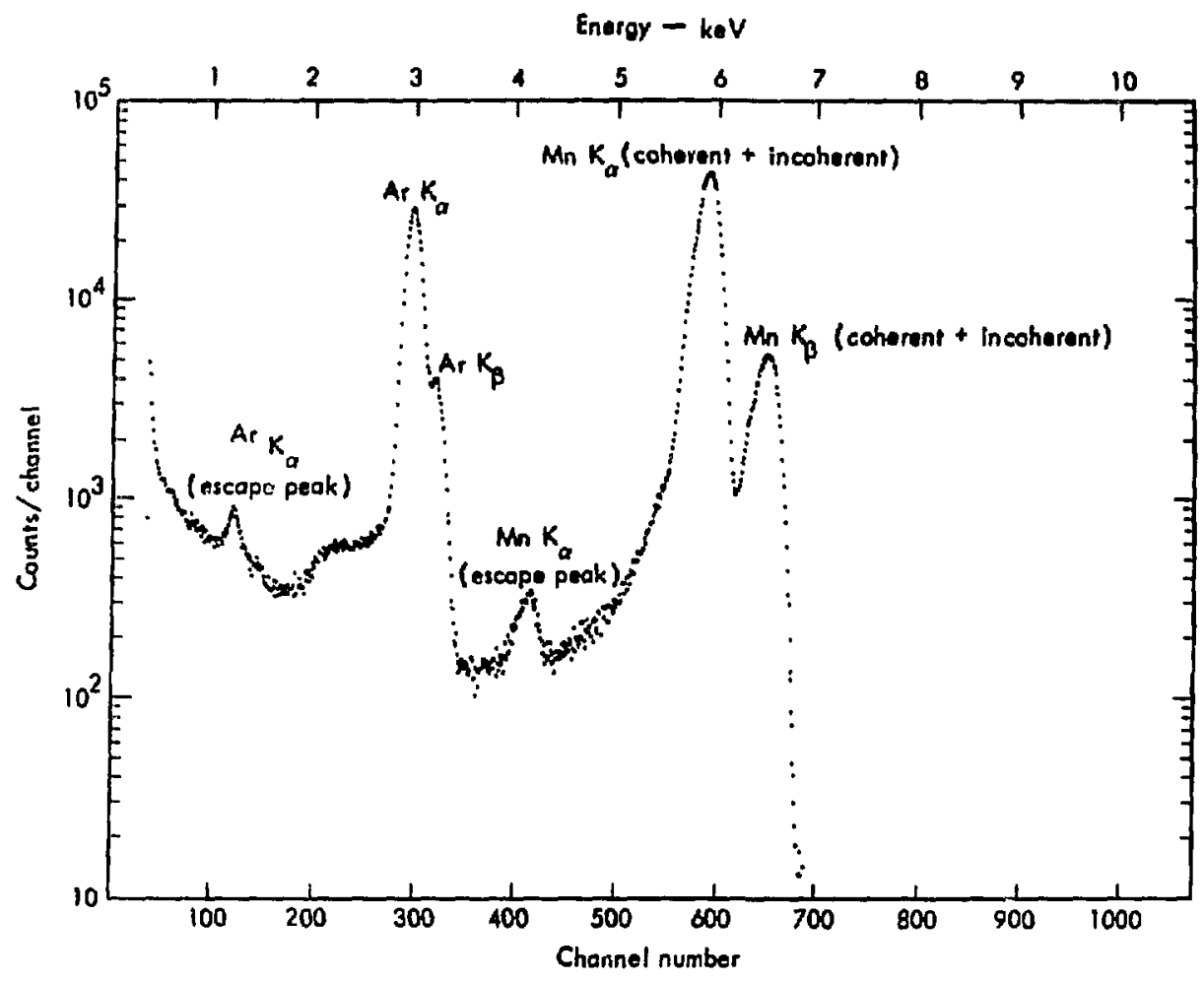

Flg. 7. Spectrum with ${ }^{55}$ Fe exciter. This is a $50 \mathrm{ksec}$ count. The major features of the spectrum are identified. At these energies the coherent and incoherent peaks cannot be separated by the detector.

\section{DATA REDUCTION}

Our approach to the data reduction problem has been fairly simple and straightforward. The methods we have developed are adequate for present purposes. More sophisticated treatment would require much more effort than would be justified by the gains expected. A ${ }^{109}$ Cd-excited spectrum will serve as an example of how we handle the data from a real sample. The other sources are handled in simllar ways, but with different gain settings and peak integration widths.

The pulse height analyzer is set up with 1024 channels, with each channel corresponding to an energy interval of $25 \mathrm{eV}$. The total range is thus 1024 $\times 25=25,600 \mathrm{ev}$, or $25.6 \mathrm{keV}$. This ts wide enough to include the elastic and inelastically scatiered silver $x$ rays from the source. The $88 \mathrm{keV}$ gamma ray is beyond the range of these spectra.

Once the energy scale has been established, the positions of the $x$ rays 


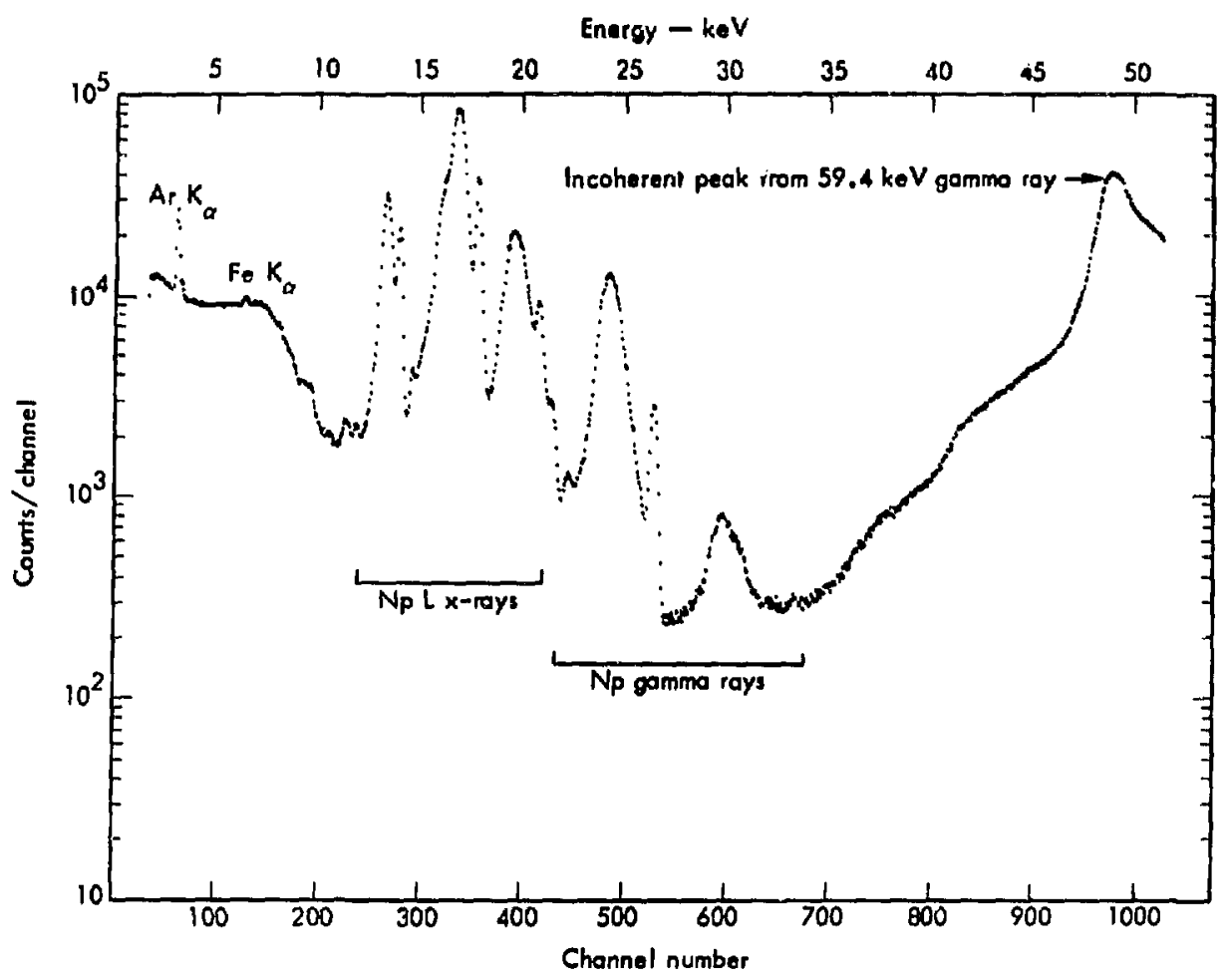

Fig. 8. Spectrum with ${ }^{241}$ Am exciter. Almost all of this complicated spectrum is from the source itself. In this form it is useful for only a few elemerts.

from each element are known. The system is stable enough so that drift is not a serious problem. As an example, the $\mathrm{Fe} \mathrm{K}_{\alpha}$ energy is $6.4 \mathrm{keV}$, so its peak will be centered in channel $6400 / 25$ $=256$. The resolution (FWHM) at this energy is about $190 \mathrm{eV}$, or 7.6 channels. Thus the peak will be at one-half its maximum height near channels 252 and 260.

Integrating to half maximum is nearly optimal for our purpose. ${ }^{2}$ The resolution is only a slight function of energy, however, so rather than vary the integration interval over the specirum, we chose to use 11 channels throughout the spectrum. This is slightly too wide for the Fe peak and slightly too narrow for the high energy end of the spectrum $(\mathrm{Zr}, \mathrm{Mo})$, but is quite adequate and has the advantage of simplicity. The same intervals are used both for calibrating the system and running samples.

For a single element the situation is very simple. We integrate the appropriate 11 channel area, subtract the number of counts which would be in those channels if the element were not there (hackground) and divide by the sensitivity fector. (The measurement of the 
sensitivity factor is described in the calluration section.) The result is micrograms of the clement in the sensllive area.

For a real sample contalning many elements soveral additional probtems arlae. One of the first problems is the determination of whlch clements are present. An obvilous answer is to identify the peaks actually present and work only with them. Thls is an attractive approach, and the way one normally analyzes $B$ complox spectrum. We wanted to avoid requiring operatur intervention for identifying the peaks from each sample, however. Unfortunately, the small memory of the NDB12 computer at the heart of our system cannot Incorporate peak identification coutines easily. Therefore it was necessary to devibe another scheme.

Since atr filter samples usually contoin only a limited number of elements, it is possible to concentrate on this limited set and treat each sample as though it contained all elemente in the set. The ND812 computer programs (software) available allowed a maximum of 16 windows or spectral areas to be selected. Two are needed for background normalization, so 14 elements can be determined in a single spectrum. This Is not a serious limitation.

It is possible to measure 50 elements with the Cd source. With $\mathrm{K} \times$ rays, we can measure from $S$ to $M o$, and with $L$ $x$ rays from the middle of the rare earths to uranium. However, of the heavy elements only $\mathrm{Pb}$ and $\mathrm{Hg}$ are likely to appear in air samples. In the light element region, $C l$ to $\mathrm{V}$ are better measured with the 55 Fe source, so thero is no need to include them. We pleked the twelve light elements $\mathrm{Cr}$, Mn, Fe, $\mathrm{Nl}, \mathrm{Cu}, \mathrm{Zn}, \mathrm{As}, \mathrm{Br}, \mathrm{Rb}, \mathrm{Sr}, \mathrm{Zr}$, and Mo in addition to $\mathrm{Pb}$ and $\mathrm{Fig}$. This leaves out Co, Ga, Ge, So, Kr, Y, and No - all untikely to occur in air filter samples. Our expertence with actual alr fllter samples verifies our cholce, with one exception. Selentum sometimea occurs in air fliter samples, but wo have never seen $\mathrm{Hg}$.

We programmed the computer to print oul an 11-channel Integral area for each of the 14 elements and two other integrals corresponding to the coherently (elastlc) and incoherently (Inelaatic or Compton) scattered $\mathrm{Ag} \mathrm{K}_{\alpha} \times$ ray. Flgure o shows a ${ }^{109} \mathrm{CJ}$ spectrum along with the location of the 14 areas chosen for integration. This plot is a linear dieplay and includes only the central region of the spectrum. The four large Ag x-ray peaks which were seen in Fig. 5 are off ecale to the right in this itgure. The sperisum is from a typical $1000 \mathrm{sec}$ fuorescence of a $24 \mathrm{hr}$ HiVol sample collected in Livermore on Whatman 41 fllter paper.

Figure 10 shows the teletype printout from the analyzer of the 16 aread for the Bpectrum shown in Fig. 9.

After the channel Integrals have been printed out, the data must be converted to micrograms of the element present. This is done on a large computer as described below. The conversion of counta to micrograms involves two major steps: (1) background subtraction, and (2) calculation of interference terms among elements. 




Fig. 9. A ${ }^{109}$ Cd-excited spectrum of a Livermore $24-h r$ HiVol sample. This is a typlcal 1000 sec count. The vertlcal lines bracketing the element aymbols at the bottom of the figure show the integration areas used in the calsulations. The corresponding channel numbers are listed in Fig. 10.

\section{(1) Background Subtraction}

The background subtraction is exiremely important, and perhaps the most difficult part of the data analysis to handle correctiy. For example, $2 \mu \mathrm{g}$ of $\mathrm{Ni}$ will give a net count equal to the background count under the $\mathrm{Ni}$ peak. Thus, for a sample containing this rather large amount of nickel, a $10 \%$ error in the background would show up as a $10 \%$ error in the nickel result. If only 0.2 microgram of $\mathrm{Nl}$ were present, a $10 \%$ background error would cause a $100 \%$ error in the nickel result. It follows that if we want to measure amounts near one microgram to a precision of $10 \%$, our background subtraction must be good to $5 \%$ or better. A series of experiments with different, support materlals (Whatman 41 , 
Millipore, IPC paper and otherg) led to a method that appears to be rood to at least $5 \%$. The procedure is to ruri a background spectrum and record the integrals from the 16 intervals described above. We found that the counts in each element interval are proportional to the sum of the $\mathrm{Ag}_{\mathrm{g}} \mathrm{K}_{a}$ coherent peak integral plus $15 \%$ of the incoherent peak integral. This is a purely empirical function with no theoretical basis, but it does work on filter paper samples.

This normalized background is calculated for faci element and subtracted from the measured colists for that element. This gives a set of net count rates for the sample.

\section{(2) Interelement Interferences}

There are several ways in which the presence of one element interferes with the measurement of another. In the region of the perioc $:=$ table near $\mathrm{Mn}$ $(Z=25)$ the $K_{\beta} \times$ ray of one element is quite close to the $K_{a} \times$ ray of the next heavier element. The $\mathrm{K}_{\beta} / \mathrm{K}_{\alpha}$ intensity ratio is about 0.2 , so the interference of the $\mathrm{K}_{\beta} \times$ ray of element $Z$ with the $\mathrm{K}_{\alpha} \times$ ray of elemcnt $\mathrm{Z}+1$ can be appreclable.

Another, more generai interference is the result of the shape of a peak produced in a $\mathrm{Si}(\mathrm{Li})$ detector. The low energy side of the peak does not drop to

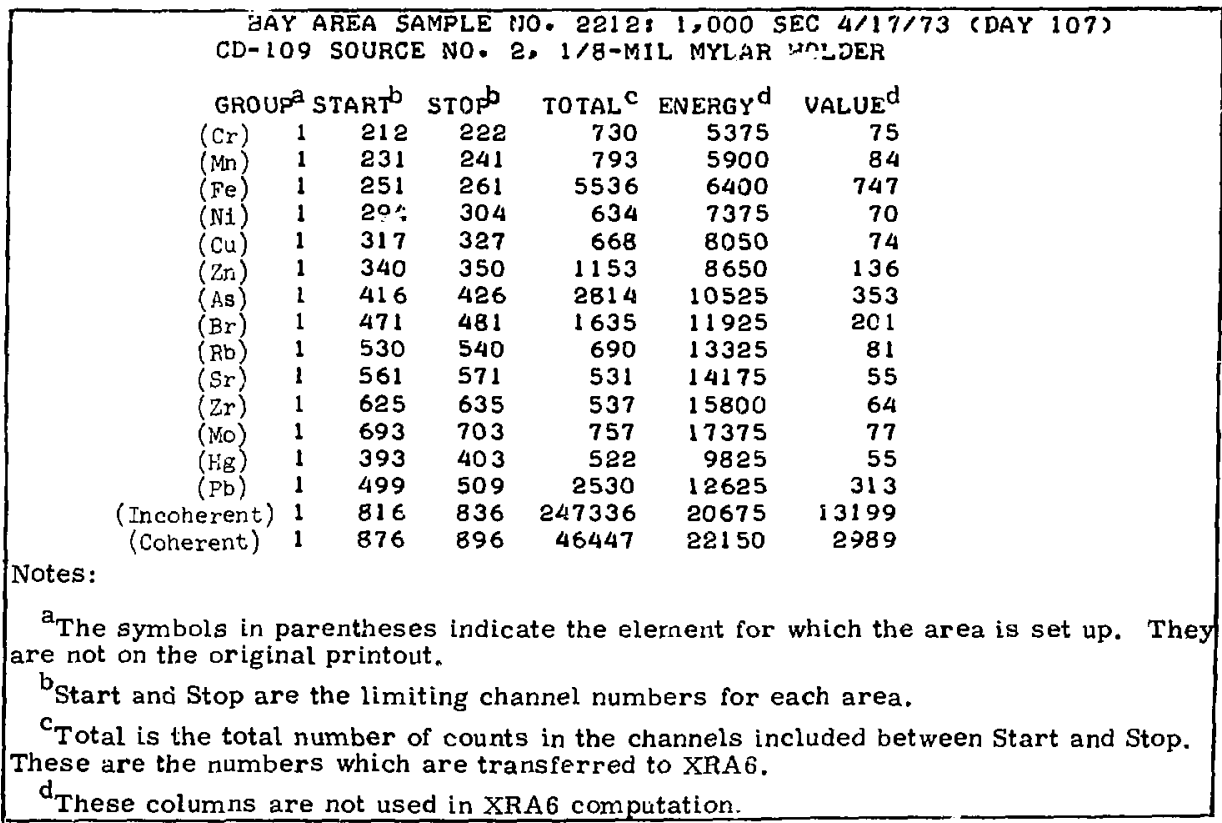

Fig. 10. Printout from the pulse height analyzer. The sample is the one whose spectrum is plotted in Fig. 9 . 
zero, but tails off with a finite contribution to ali channels below it. Thus, each element interferes to some extent with all elements which have $x$ rays at lnwer energy.

One particular interfer ence unique to this ont of elements is the $\mathrm{Pb}-\mathrm{As}$ interference. The $\mathrm{Pb} \mathrm{L}_{\alpha}$ peak and the As $K_{\alpha}$ peak are nearly identicai in energy. The $A s K_{B}$ is separale from the $\mathrm{Pb}$ peaks, but its intersity is only about $1 / 5$ that of the $K_{a^{*}}$ so it is a poor one to "se to measure As, Fortunately the $\mathrm{Pb}$ $I_{\beta}$ has no appreciable interferences from the other elements usually present and it has an intensity nearly equal to the $L_{\alpha}$, so the determination of $\mathrm{Pb}$ with the $\mathrm{I}_{\beta}$ $x$ ray is very good. Then, As can be determined by subtracting from the mixed $\mathrm{Pb}$-As peak the amount of $\mathrm{Pb} \mathrm{L}_{a}$ corresponding to the measured $\mathrm{Pb} \mathrm{L} \beta$. This procedure is adequate if the As and $\mathrm{Pb}$ abundances are similar, but for ordinary air filter samples $\mathrm{Pb}$ is quite abundant and $A s$ is present only in very $\because$ rall amounts. In this situation the $A s$ measurement is very uncertain.

Given the existence of these various types of interferences, the problem is to make the appropriate corrections in as simple a way as possible.

The obser"red total counts, $T_{i}$, in any one channel integral are the sum of a set of contributions. The major contribution will normally be the courts, $N_{i}$, produced by the element for which the integral has been set up. Other elements present may contribute counts to $T_{i}$. The number produced by element $j$ will be some fraction, $A_{i j}$, of the counts, $N_{j}$, produced in its chanrel integral. Finally, there is the background count rate in each inrugral, which was discussed above.

To make the above generalized description clear, consider a simplified example of three elements, $\mathrm{Fe}, \mathrm{Ni}$, and $\mathrm{Cu}$. The total counts in the Fe channels are $\mathrm{T}_{F e}$. These will be the sum of the counts produced by $\mathrm{Fe}$ itself, $\mathrm{N}_{\mathrm{Fe}}$ the background counts, $\mathrm{B}_{\mathrm{Fe}}$, and the counts produced in the Fe channels by $\mathrm{Ni}$ and Cu. If the co\%: in the Ni channels produced by $\mathrm{Ni}$ itself are $\mathrm{N}_{\mathrm{NL}}$, and the counts in the Ca channels produced by $\mathrm{Cu}$ are $\mathrm{N}_{\mathrm{Cu}}$, then the counts in the $\mathrm{Fe}$ channels produced by $\mathrm{Ni}$ and $\mathrm{Cu}$ are $\mathrm{A}_{\mathrm{Fe}, \mathrm{Ni}} \times \mathrm{N}_{\mathrm{Ni}}$ and $\mathrm{A}_{\mathrm{Fe}, \mathrm{Cu}} \times \mathrm{N}_{\mathrm{Cu}} \mathrm{re}-$ spectively. The A terms are the interelement interference factors. The term ${ }^{A} \mathrm{Fe}, \mathrm{Nl}$ is the number of counts which will be produced in the Fe channels for each, count produced by $\mathrm{Ni}$ in the $\mathrm{Ni}$ channels. ${ }_{\mathrm{Fe}} \mathrm{Cu}$ is the analogous term for the $C u$ contribution.

Thus, the equation for the total counts produced in the $\overrightarrow{F e}$ channels by a sample containing $\mathrm{Fe}, \mathrm{Ni}$, and $\mathrm{Cu}$ is:

$$
\begin{aligned}
T_{\mathrm{Fe}}=\mathrm{B}_{\mathrm{Fe}}+ & \mathrm{N}_{\mathrm{Fe}}+\mathrm{A}_{\mathrm{Fe}, \mathrm{Ni}} \times \mathrm{N}_{\mathrm{Ni}} \\
& +\mathrm{A}_{\mathrm{Fe}, \mathrm{Cu}} \times \mathrm{N}_{\mathrm{Cu}}
\end{aligned}
$$

The simplest procedure is to subtract the background first, as described in the backgroul: section. This gives us a net count, $C_{\mathrm{Fe}}=\mathrm{x}_{\mathrm{Fe}}-\mathrm{B}_{\mathrm{Fe}}$. The simplified equation then becomes:

$$
\begin{aligned}
\mathrm{C}_{\mathrm{Fe}}=\mathrm{N}_{\mathrm{Fe}}+\mathrm{A}_{\mathrm{Fe}, \mathrm{Ni}} & \times \mathrm{N}_{\mathrm{Ni}} \\
& +\mathrm{A}_{\mathrm{Fe}, \mathrm{Cu}} \times \mathrm{N}_{\mathrm{Cu}} .
\end{aligned}
$$

To make the equation more symmetrical, we can insert the factor $A_{F e, F e}=1.0$, 


$$
\begin{gathered}
\mathrm{C}_{\mathrm{Fe}}=\mathrm{A}_{\mathrm{Fe}, \mathrm{Fe}} \times \mathrm{N}_{\mathrm{Fe}}+\mathrm{A}_{\mathrm{Fe}, \mathrm{Ni}} \times \mathrm{N}_{\mathrm{Ni}} \\
+\mathrm{A}_{\mathrm{Fe}, \mathrm{Cu}} \times \mathrm{N}_{\mathrm{Cu}} .
\end{gathered}
$$

The generalized equation for the $i$ th element of a set of n elements becomes:

$$
\begin{aligned}
C_{i}=A_{i, 1} & \times N_{1}+A_{i, 2} \times N_{2}+\ldots \\
& +A_{i, i} \times N_{i}+\ldots A_{i, n} \times N_{n} .
\end{aligned}
$$

For the set of 14 elements described for the ${ }^{109} \mathrm{Cd}$ source, there will be 14 such equations with 14 unknowns. The $C_{i}$ terms are the output of the pulse height analyser after correction for background. The $\mathrm{N}_{\mathrm{i}}$ terms are the values we want to determine.

The $A_{i, j}$ terms (the interference matrix) are measured as part of the calibration procedure for each element. A sample of the element is counted and the counts in each of the 14 areas are recorded. The net counts in each area (i.e. after background subtraction) are then divided by the net counts in the area corresponding to the element being counted. These ratios are the $\hat{i}_{i, j}$ values, with the $A_{i, i}$ terms all being unity by definition.

With a few exceptions the $A_{i, j}$ values are quite small, usually between 0.002 and 0.005 . The exceptions are the cases where there are actually two overlapping $x$ rays, surh as the $\mathrm{Pb}-\mathrm{As}$ interferences and the $K_{\alpha \alpha}-K_{\beta}$ Interferences of neighboring elements mentioned earlier.
With thit total counts measured and the backgrounds and interelemenc interferences known, we have all the information necessary to solve the 14 equatione for the 14 Individual element contributions. Solving 14 simultaneous equations is a trivial problem for a large computer.

Our computer program (XRA6) is set up to use a teletype for both input and output. We type in a sample identification, the channel integrals printed out by the analyzer, the date of the count and the duration of the count. It then calculates the background for each element, solves the 14 simultaneous equations, corrects the calibration factors for the decay of the exciter, uses the corrected calibration factors to convert the individual element counts to micrograms and prints out the results. It also $\mathrm{c}$ iculates the standard deviation of the final result. Thls takes into account only the uncertainty caused by counting statistice. The calibration uncertainties and any systematic errors must be treated separately.

Figure 11 is an example of the computer input and output as it appears on the teletype. This sample is the same one whose spectrum is shown in Fig. 9 and whose integrated areas are shown in Fig. 10 .

The amounts listed in the "Microgram" column are the amounts in the sensitlve area of the system. Any necessary absorption corrections must be applied by hand as described in Appendix B. 


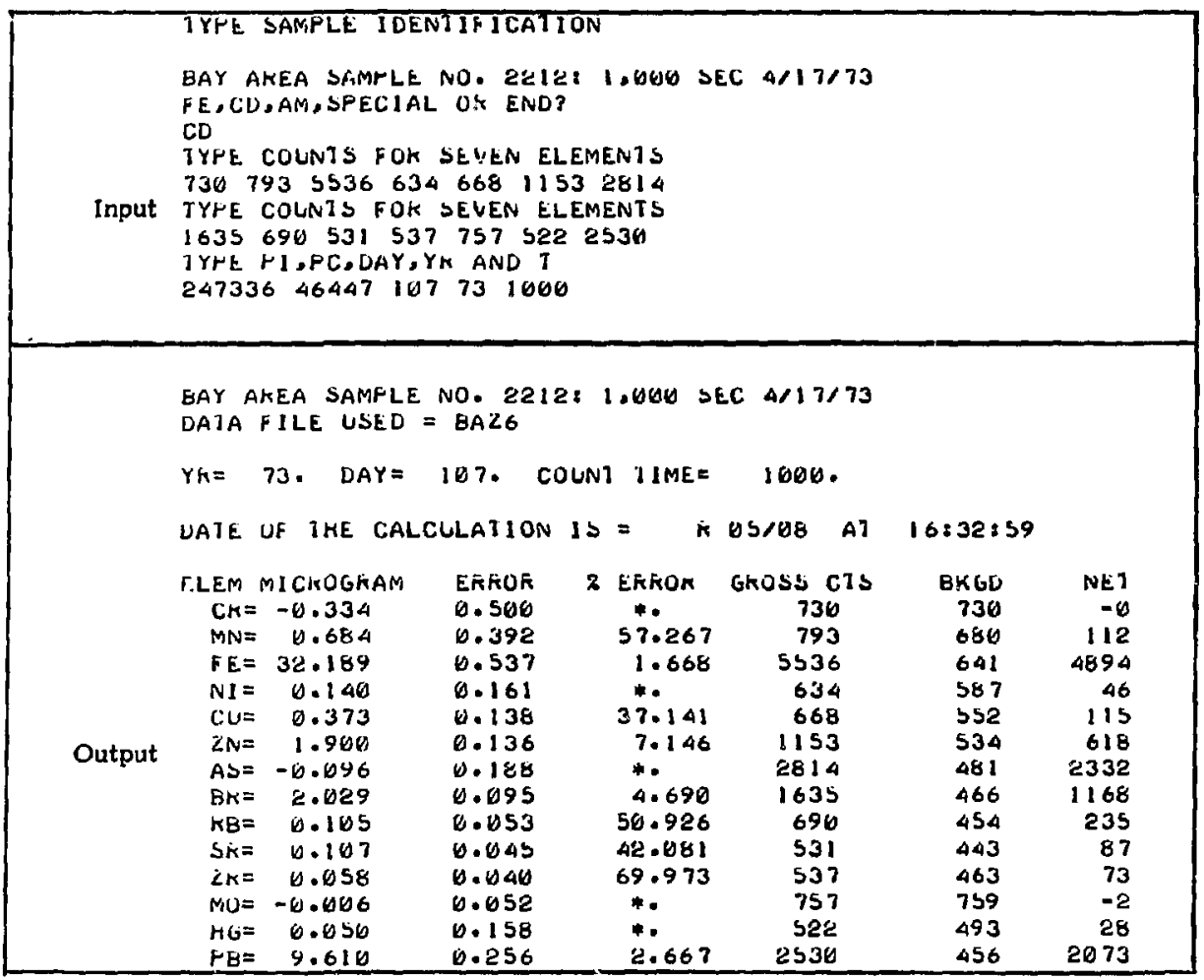

Fig. 11. Input and output from the $x$-ray analysis program XRA6. The sample is the one whose spistrum is plotted in Fig. 9. The column headings are more or less self-explanatory. Error is the $1 \sigma$ counting statistical uncertainty. Any uncertainty greater than $100 \%$ is 1 isted as an asterisk. An uncertainty 0 . $33.3 \%$ would be a 30 peak, so the Cu peak is close to $3 \sigma$. The only el ments in this sample with measurable values are $\mathrm{Fe}, 2, \mathrm{n}, \mathrm{Br}$, and $\mathrm{Pb}$.

\section{Calibration}

\section{CALIBRATION FROCEDURES}

Calibration of the system is simple in principle. A known amount of an element is placed on the sample holder and the count rate in the appropriate energy range is measured. This gives a sensitivity expressed in counts per second per microgram (cps/ug). When a sample is measured this sensitivity can be used to convert the measured $\mathrm{cps}$ to micrograms.

There are a few practical problems that show up in the preparation and use of standards for calibraitinn. Two of the most important ones are uniformity and 
tnickness of material. In our system, uniformity of distribution over the sample area !s unimportant if the diameter of the standard is less than about 0.8 in. This is the result of the near uniformity of response over this area.

The thlckness of the standard material, however, can be very important. The low energy $x$ rays being measured are strongly absorbed by almost any material; if the sample has any apprectable thlciencas a correction must be made. Ideally, a standard would be infinitely thin, but obviously a compromise must be reached between no absorption and enough mass to measure a trace element accurately.

With these considerations in mind, we made measurements on three kirds of standards:

\section{1) Very Thin, Vapor Deposited Standards on $1.5 \times 10^{-4}$ in. Mylas: Backing}

The deposits are $1 \mathrm{in}$, in diameter and are prepared by MicroMatter, Inc., Seattle, Washington. These are thin enough to have no appreciable absorption for the elements of interest to us. The weights of the deposits are quoted to a precision of $5 \%$. The deposits are not entirely uniform, but the 1 in. diameter is nearly within our area of uniform response, so the slight nonuniformity introduces no appreciable error.

2) "Infinitely Thick" Samples of Pure Elements and Compounds

These are motal foils or pressed wafers which are thick enough $>5$ absorption mean free paths) so that additional thickness adds no signal. For these standards self-absorption corrections are all-important, of course. The method of treating the data from these standards is discussed in

Appendix B. These standards are most useful where absorption effects are the greatest, e.g., for the elements measured with the ${ }^{55}$ Fe source.

\section{3) Freeae-Dried Samples on Filtex Paper}

We cut a 0.65 in. dian circle from Whatman 41 paper and placs li on a small sheet of Teflon. We then pipet $25 \mu l$ of a standard solution of the deslred element onto the paper, making sure that the transfer is quantitative. This volume is jugt enough to wet the paper completely, but not enough to. leave a vislble liquid surface. This assures that the material is distributed uniformly over the area of the paper.

The next step is to freeze the solution by putting the Tenon sheet holding the fulter paper onto a plece of dry ice. The Teflon sheet and the frozen sample are then put into a vacuum system and pumped for at least two hours. By this time sublimation has removed most of the water, leaving the elemental standard neariy uniformly distributed. If the solution had been evaporated at room temperature or under a heat lamp, a large fraction of the salt would have concentrated around the edge of the paper.

Absorption corrections for these samples are not negligible, but are small and measurable. These standards are very useful for $x$ rays above about $5 \mathrm{keV}$. For lower energies the absorption correctior:s become so large that 
one $\mathrm{might}$ as well use infinitely thick samples. Because the freeze-dried standards are unifor $m$, the small absorption correction can be made accurately. In addition, most of the absorption is caused by the filter paper, so its absorption coefficlent can be measured directly.

For any sample with a diameter greater than about 0.8 in. an area correction must be made. Recall that beyond this diameter the sensitivity falls off rapidly. We chose the inner 0.5 in. diam as our standard area for calibrations. With this standard the effectlve area of an infinitely large sample ls $5.87 \mathrm{~cm}^{2}$. The effective area of a $1 \mathrm{in}$, diam sample (geometric area $5.07 \mathrm{~cm}^{2}$ ) Is $4.58 \mathrm{~cm}^{2}$ for the ${ }^{109} \mathrm{Cd}$ source, i.e., it has a count rate 4.58 times that of a eample with an area of $1 \mathrm{~cm}^{2}$. These effective areas were determined by measuring samples of various diameters cut from a uniform sample.

\section{SENSITIVITIES}

The sonsitivitiea in cps per milligram for the elemonts we normally measure are listed in Table 1. For the $C d$ source the counts for each element are the sum of the counts in 11 channels centered as nearly as possible in the peak channel as described in the section on data handling. Each channel corresponds to $25 \mathrm{eV}$, so the 11 channel area is $275 \mathrm{eV}$ wide. For the Fe source, the counts are 21 channel sums; each channel corresponds to $10 \mathrm{eV}$ so these areas are $210 \mathrm{eV}$ wide. For the ${ }^{24 i} \mathrm{Am}$ source the number of channels is variable, depending on the individual situation.

One convenient feature of $x-$ ray phenomena is that, with the exception of

Table 1. Detection sensitivities of selected elements in counts per second per millgram.

\begin{tabular}{|c|c|c|c|c|c|c|c|c|}
\hline \multicolumn{3}{|c|}{${ }^{55} \mathrm{Fe}$} & \multicolumn{3}{|c|}{${ }^{109} \mathrm{Cd}$} & \multicolumn{3}{|c|}{241 Am } \\
\hline $\begin{array}{l}\text { Atomic } \\
\text { Number }\end{array}$ & Symbol & $\frac{\overline{c p g}}{m g}$ & $\begin{array}{l}\text { Atomic } \\
\text { Number }\end{array}$ & Symbol & $\frac{\mathrm{cps}}{\mathrm{mg}}$ & $\begin{array}{l}\text { Atomic } \\
\text { Number }\end{array}$ & Symbol & $\frac{\overline{c p s}}{m g}$ \\
\hline 15 & $\mathbf{P}$ & 4 & 24 & $\mathrm{Cr}$ & 122 & 48 & $\mathrm{Cd}$ & 446 \\
\hline 16 & $\mathbf{S}$ & 9.52 & 25 & $\mathbf{M n}$ & 153 & 49 & In & 428 \\
\hline 17 & $\mathrm{Cl}$ & 19.7 & 26 & $\mathrm{Fe}$ & 203 & 52 & Te & 469 \\
\hline 19 & $\mathrm{~K}$ & 58.7 & 28 & $\mathrm{Ni}$ & 322 & 55 & $\mathrm{Cs}$ & 439 \\
\hline 20 & $\mathrm{Ca}$ & 92.8 & 29 & $\mathrm{Cu}$ & 367 & 56 & $\mathrm{Ba}$ & 391 \\
\hline 21 & Sc & 130 & 30 & $Z_{n}$ & 427 & 58 & $\mathrm{Ce}$ & 397 \\
\hline 22 & $\mathrm{Ti}$ & 185 & 33 & As & 615 & 60 & Nd & 355 \\
\hline 23 & v & 252 & 35 & $\mathbf{B r}$ & 755 & 63 & Eu & 279 \\
\hline 24 & $\mathrm{Cr}$ & 34.5 & 37 & $\mathbf{R b}$ & 889 & & & \\
\hline & & & 38 & $\mathrm{Sr}$ & 958 & & & \\
\hline & & & 40 & $\mathrm{Zr}$ & 1100 & & & \\
\hline & & & 42 & Mo & 1200 & & & \\
\hline & & & 80 & $\mathrm{Hg}_{\mathrm{g}}$ & 286 & & & \\
\hline & & & 82 & $\mathrm{~Pb}$ & 289 & & & \\
\hline
\end{tabular}




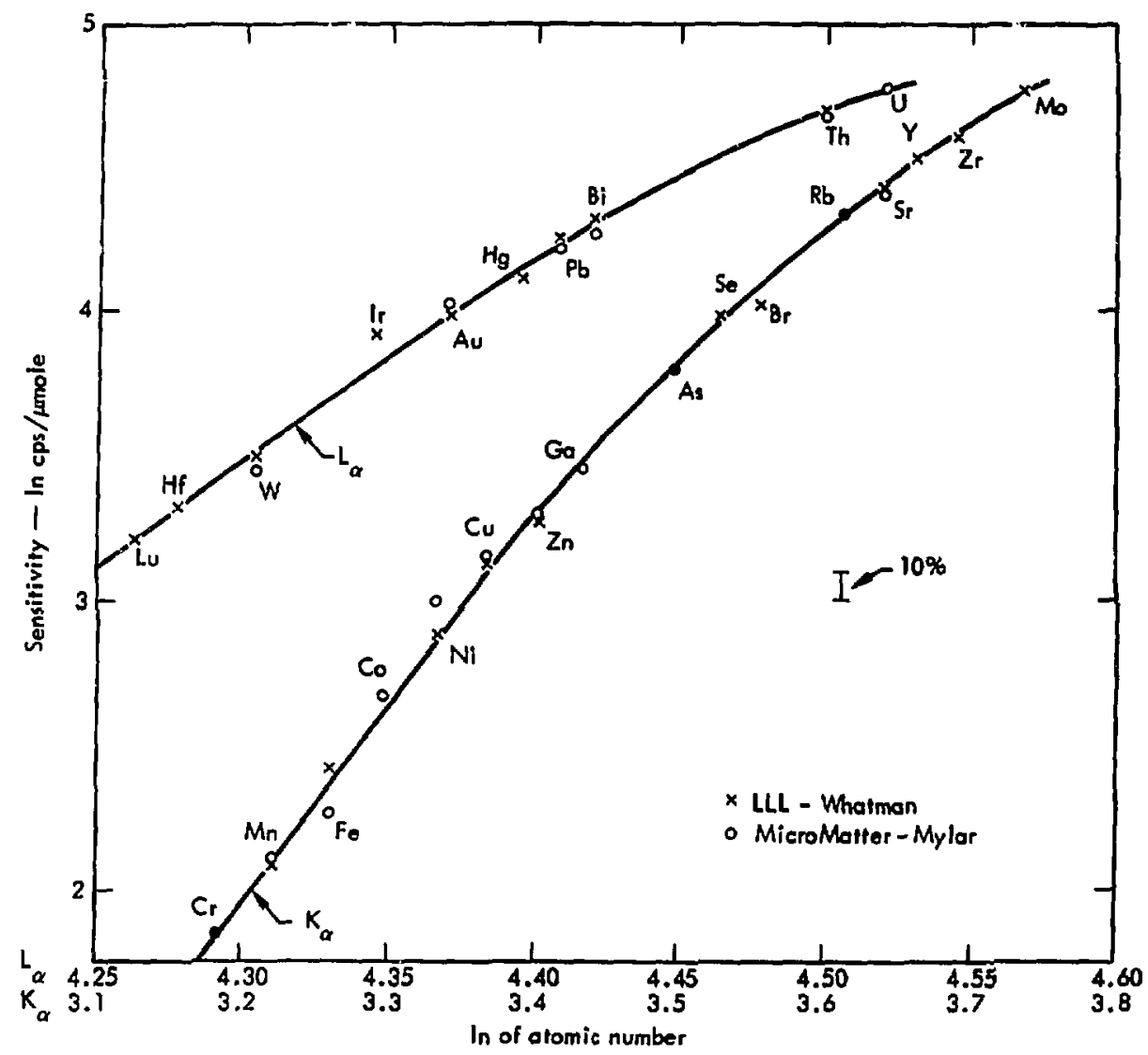

Fig. 12. Plots of the natural logarithm of sensitivity in cps per micromole vo logarithrn of atomic number for the $109 \mathrm{Cd}$ source. The upper curve is for the $L$ rays of the elements from $L u$ to $U_{\text {; }}$ the lower curve is for the $K$ $x$ rays of the elements from $\mathcal{C} r$ to $\mathrm{Mo}$. These plots are used for interpolation and for smoothing the calibration data. The lines are merely to guide the eye.

energies in the neighborhood of absorption edges, they are smooth functions of atomic number. Thus we would expect a plot of the calibration factors vs $\mathrm{Z}$ to be a smooth curve.

We have plotted in Figs. 12 and 13 the calibrations as the logarithm of cps per mole $v a$ the logarithm of atomic number. This type of plot gives nearly straight lines. If the calibration point for an element is in error, it falls off the line and is therefore fairly obvious. Thus, the calibration for any given element is improved by the knowledge of the sensitivities for nearby elements. For the calibration values given in Table 1, we have used values taken from the amooth curves rather than the individually 




Fig. 13. Plot of natural logarithm of sensitivity in cps per millimole vs logarithm of atomic number for the ${ }^{55} \mathrm{Fe}$ source.

measured values. Elements for which we did not prepare standards are taken from the smooth curve also, and are probably nearly as precise as those actually measured. The calibration points for the various types of atandards are included on the curves to show the degree of agreement among them. We have not included a calibration curve for the ${ }^{241}$ Am source because of the exciter spectrum's complexity.

Based on these curves and the results of the intercalibration data, we conclude that the absolute accuracy of our calibrations is about $\pm 10 \%$.

\section{DETECTABILITIES}

There has been a certain amount of confusion in terminology in the x-ray fuorescence field. In particular, the terms sensitivity and detectability have been used in unusual ways.

In analytical chenistry, sensitivity ordinarily refers to the signal produced by some unit of sample. In x-ray fluorescence it is cominion to measure counts per second produced by a microgram of an element. These are the values tabulated in the previous section. The minimum amount detectable by an instrument or technique is usually called the detectability. Some of the recent investigators in $x$-ray nuorescence have called this the sensitivity. We will use the term detectabnity in conformity with ordinary analytical usage.

The detectability depends on the sensitivity, of courge, but is ultimately determined by the signal to noise (background) ratio. We have chosen to use the common definition of the detectability as a net signal which is equal to three atandard deviations ( $\sigma$ ) of the background.

In our aystem the background is the spectrum produced in the detector by radiation backscattered from the exciter source. The background under a peak is the number of counts which would occur in the channelis corresponding to the peak if the element producing it were not present. If the number of background counts is $\mathrm{N}_{\mathrm{b}}$, the standard deviation is $\sqrt{N_{b}}$. The minimum number of counts above background, $\mathrm{N}_{\mathrm{m}}$, to meet the detectability criterion is then $3 \mathbb{N}_{b^{-}}$. The minimum detectable count rate is given by

$$
\frac{N_{m}}{t}=\frac{\sqrt[3]{N_{b}}}{t}
$$

where $t$ is the counting time in seconds. 
If the sensitivity in $\mathrm{cps} / \mu \mathrm{g}=k$, then the detectability in microgram is

$$
\frac{\sqrt[3]{N_{b}}}{t k}
$$

The number of backg "ound counts is the background rate, $R_{b}$, times the sounting time: $N_{b}=R_{b} \cdot t$, thus the detectability is given by

$$
\frac{\sqrt[3]{\mathrm{R}_{b} t}}{k t}=\frac{\sqrt[3]{R_{b}}}{k \sqrt{t}} .
$$

Therefore, the minimum detectable amount decreases as the square root of the counting time and increases as the square root of the background count rate.

With our system the background count rate is determined by the strength of the exciter source and by the nature of the sample. Thus, for a given exciter and a given sample, the detectability can be changed only by changing the counting time. However, since the detectability varies inversely as the square root of the time, gains come slowly after the first few minutes.

For air filter samples on Whatman 41 paper counted for $1000 \mathrm{sec}$, the detectabilities are listed in Table 2. The values are given in three forms: 1) total micrograms in the sensitive area of the system, 2) nanograms per square centimeter of the filter, and 3 / nanograms per cubic meter of air for a typical 24-hr Hivol sampler, which filters about $1400 \mathrm{~m}^{3}$ of air through a $425 \mathrm{~cm}^{2}$ filter area. Figure 14 is a plot of detectabilities vs. atomic number.

The $\mathrm{Cu}$ peak in Fig. 9 just meets our criterion for minimum detectability. As can be seen, it is clearly visible.
This criterion will therefore rarely, if ever, ialsely indicate the presence of an element.

Other filter media will give different detectabilities. Materials which are low $\mathbf{Z}$ and thinner than Whatman 41 will give lower detectabilities. Filters such as Millipore and Nucleopore would thus be better than Whatman 41 as far as detectability limits are concerned. Thls would also be true of impactor media such as thin Mylar or Tefion folls, or even aluminum if it were thin enough.

A glass fiber fllter medium, on the other hand, is very bad for two reasons. First, it is heavier, giving more backscatter. Second, it contains large amounts of the elements present in typical aerosols, making large background corrections. A spectrum of a clean glass fiber filter, with no sample on it, is shown in Fig. 1 . This shows clearly why glass fllters are unsuitable for collecting aerosol samples for elemental analysia. A Whatman 41 blank spectrum appears in Fig. 16 as a comparison.

\section{ABSORPTION CORRECTIONS FOR HiVol SAMPLES}

$X$ rays in the energy range of interest (approximately 2 to $40 \mathrm{keV}$ ) are fairly strongly absorbed by most materials. Therefore, we must expect both the exciting radiation and the emitted $X$-rays to be partially absorbed by the samples themselves. Furthermore, we must be able to correct for this absorption if we are to obtain quantitative analyses.

In actual air filter samples the absorption corrections range from a few percent up to as much as a factor of two 
Table 2. Detectability 1 imite for various elements in terms of minimum sample waight, weight per unit area of filter paper, and weight per unit volume of air. All samples on Whatman 41 paper, counted for $1000 \mathrm{sec}$.

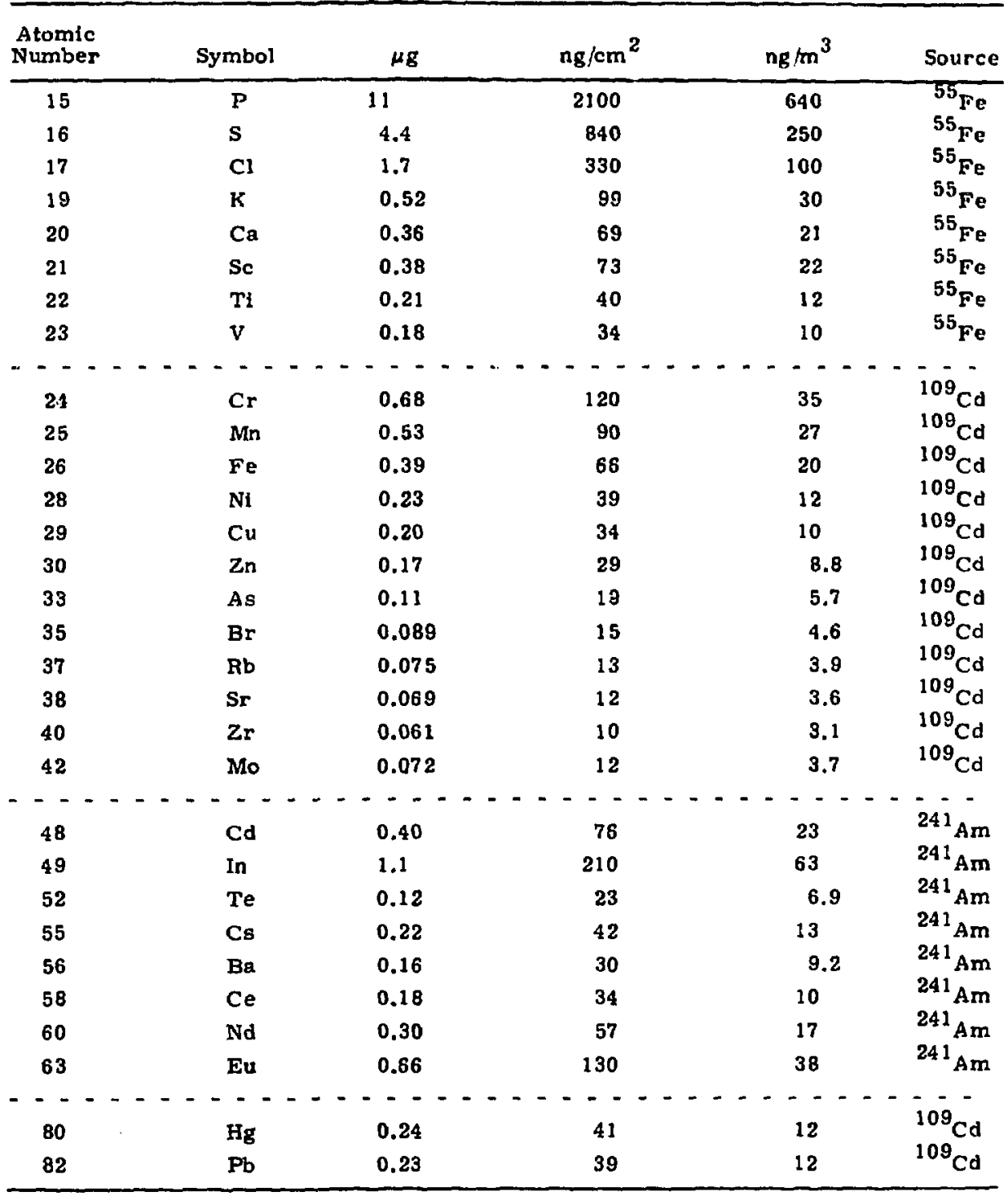




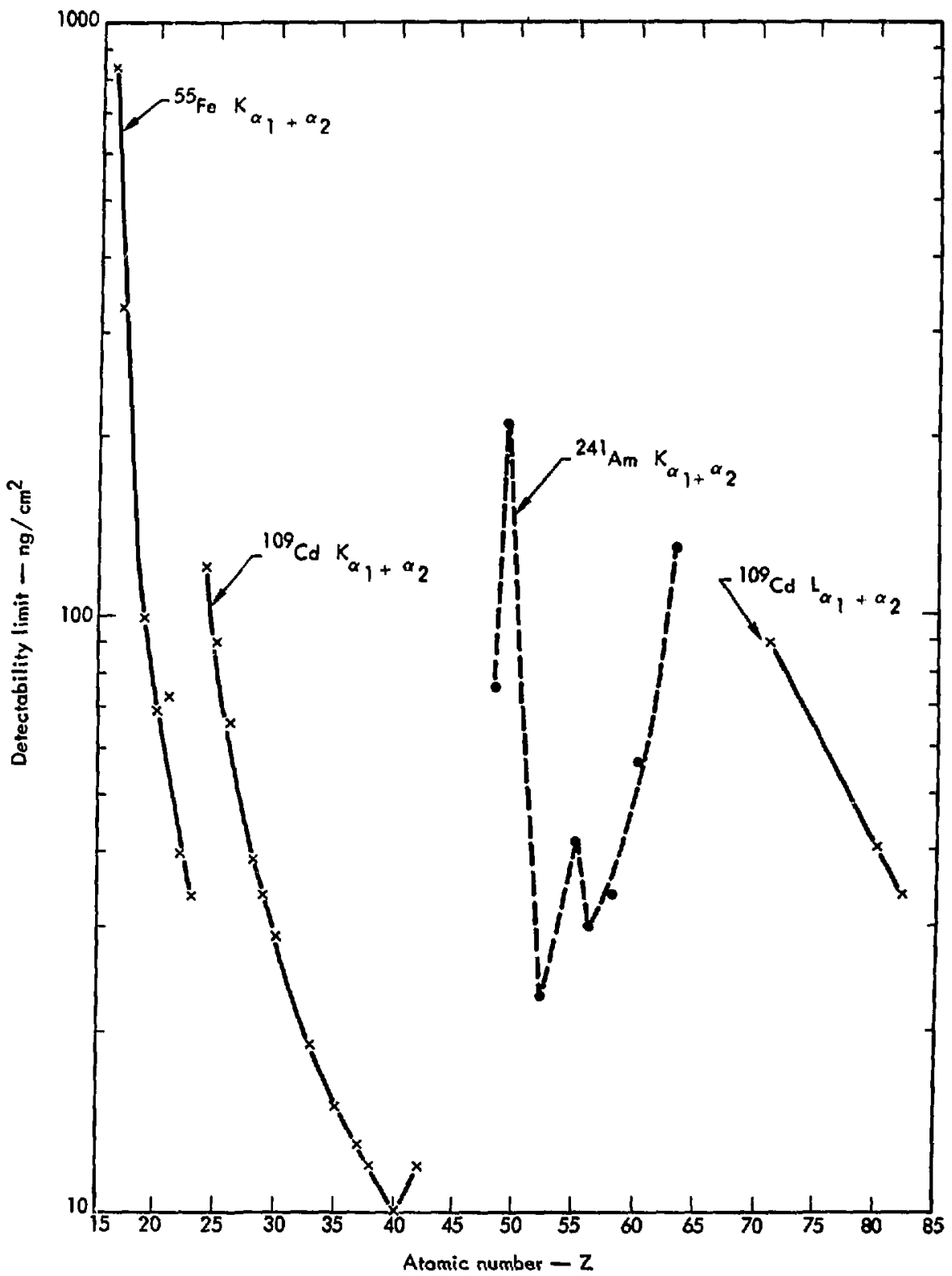

Fig. 14. Detectabiuity limits for selected elements with all three sources. Unitg are nanograms of element per square centimeter of filter. 


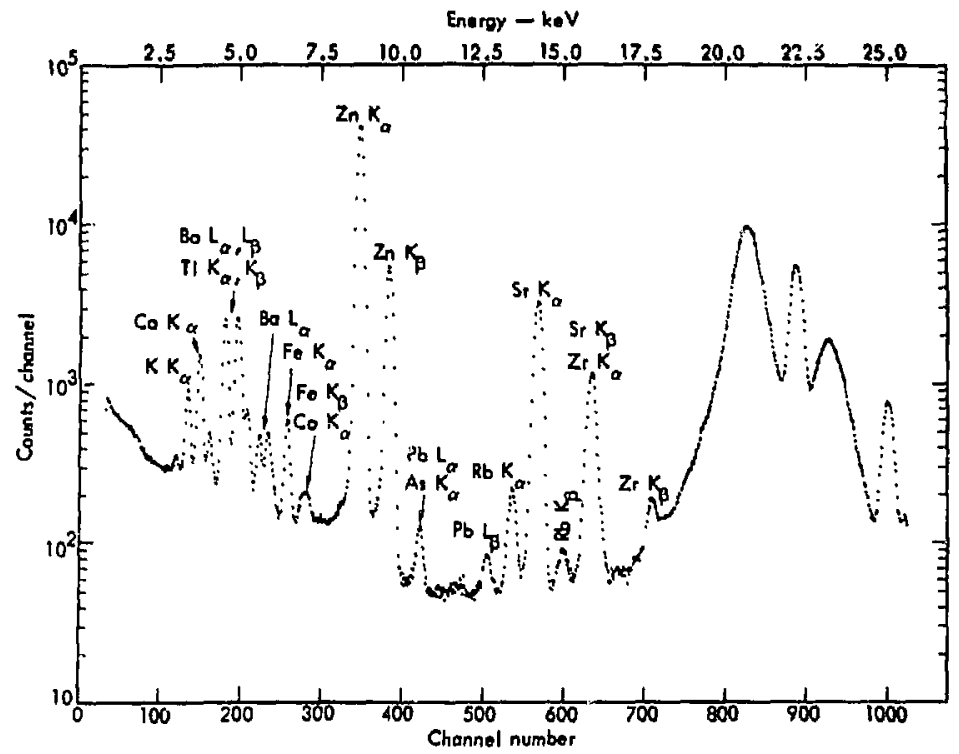

Fig. 15. Background spectrum of a typir il glass fiber filter, $10 \mathrm{ksec}$ count, $109 \mathrm{Cd}$. Note the leste number of interfering peaks. Compare with Fig. 16.

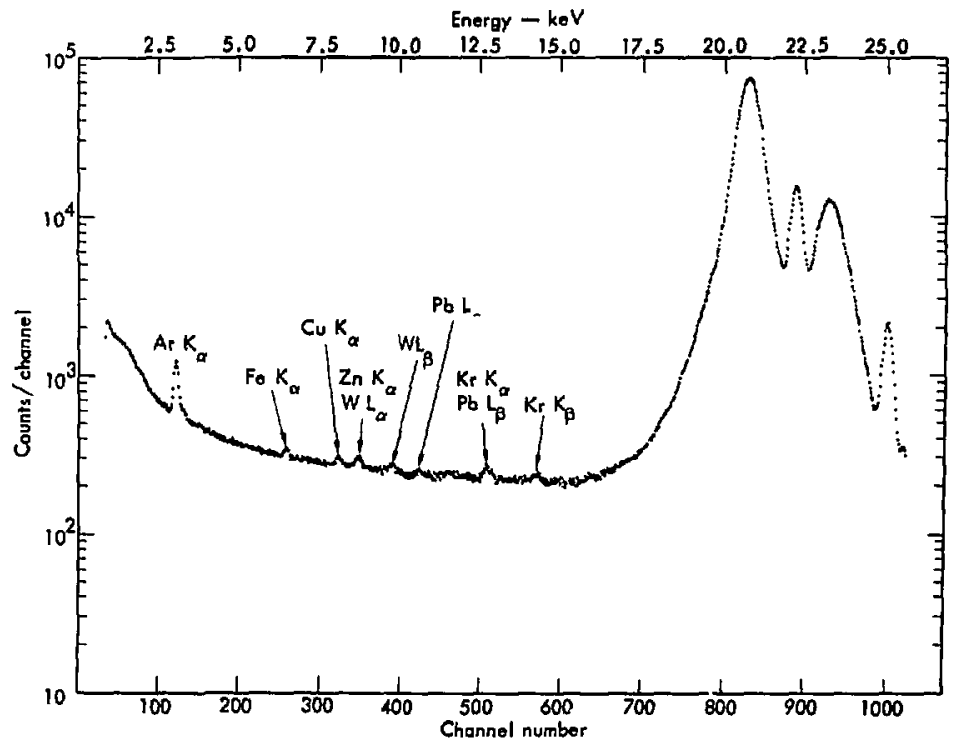

Fig. 16. Bacliground spectrum of Whatman 41 paper, $50 \mathrm{ksec}$ count, ${ }_{105} \mathrm{Cd}$. This paper is not completely free of impurities, but it is adequately clean for our purposes. 
depending on the element being analyzed and the nature of the filter medium.

Tablo 3 lists the absorption correction factors used for Whatman $41 \mathrm{HiVol}$
Bamples measured with the ${ }^{55} \mathrm{Fe}$ and ${ }^{109} \mathrm{Cd}$ sources. The method of calculating these correction factors is described in Appendix $B$.

Table 3. Absorption correction factors used for Whatman 41 HiVol samples. ${ }^{2}$

\begin{tabular}{|c|c|c|c|c|c|}
\hline \multicolumn{3}{|c|}{${ }^{55} \mathrm{Fe}$ Source } & \multicolumn{3}{|c|}{${ }^{109} \mathrm{Cd}$ Source } \\
\hline Element & $\begin{array}{c}\text { Coefficlent } \\
\mathrm{cm}^{2} / \mathrm{mg}\end{array}$ & Correction $^{c}$ & Element & $\begin{array}{l}\text { oefficient } \\
\mathrm{cm}^{2} / \mathrm{mg}\end{array}$ & Correction $^{c}$ \\
\hline 5 & 0.305 & 1.6 & $\mathrm{Cr}$ & 0.026 & 1.05 \\
\hline $\mathrm{Cl}$ & 0.238 & 2.0 & $\mathrm{Mn}$ & 0.021 & 1.04 \\
\hline $\mathrm{K}$ & 0.146 & 1.3 & $\mathrm{Fe}$ & 0.017 & 1.03 \\
\hline $\mathrm{Ca}$ & 0.118 & 1.24 & $\mathrm{Ni}$ & 0.011 & 1.02 \\
\hline Sc & 0.096 & 1.20 & $\mathrm{Cu}$ & 0.0091 & 1.02 \\
\hline $\mathbf{T i}$ & 0.078 & 1.16 & $\mathrm{Zn}$ & 0.0076 & 1.02 \\
\hline \multirow[t]{8}{*}{$\mathrm{V}$} & 0.065 & 1.13 & As & 0.0045 & ${ }_{1}^{d}$ \\
\hline & & & $\mathrm{Br}$ & 0.0033 & 1 \\
\hline & & & $\mathrm{Rb}$ & 0.0026 & 1 \\
\hline & & & $\mathrm{Sr}$ & 0.0023 & 1 \\
\hline & & & $\mathrm{Zr}$ & 0.0018 & 1 \\
\hline & & & Mo & 0.0015 & 1 \\
\hline & & & $\mathrm{Hg}$ & 0.0051 & 1 \\
\hline & & & $\mathrm{Pb}$ & 0.0029 & 1 \\
\hline
\end{tabular}

${ }^{\mathrm{a}}$ See Appendix $\mathrm{B}$ for details of the calculation.



$c_{\text {The correction factor, } C=(b+a / b)}\left[\left(1-e^{-b D}\right) /\left(1-e^{-(b+a) D}\right)\right]$ (Equation $B-9$, Appendix B). In this expression $D$ is the thickness of the sample and $b$ is assumed to be $0.5 \mathrm{~cm} 2 / \mathrm{mg}$ for all elements except $\mathrm{Cl}$, for which is assumed to be 0.1 .

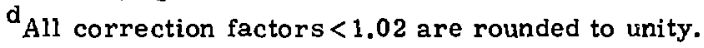

\section{Experimental Results}

\section{ACCURACY}

National Bureau of Standards Orchard Leaves

We measured the NBS Standard

Reference Material 1571 (orchard leaves) with our ${ }^{109} \mathrm{Cd}$ source and obtained good data on nine trace elements.
Approximately $250 \mathrm{mg}$ of the powdered material was pressed into a 1 in. diam wafer using a hydraulic press. It was then weighed accurately. The correction to dry weight was made by measuring the weight loss of other batches of the material when it was dried according to NBS specifications. The weight loss was 
4.6\%. The $250 \mathrm{mg}$ weight was chogen for two reasons: 1) NBS atates that this is the minimum sample which can be expected to be representative of the material, and, 2) smaller samples were very thin and fragile.

Because of the thickness it was necessary to make the absorption corrections very carefully. We measured the absorption of the $x$ rays from four elements by the sample itself. The four were $\mathrm{Cr}, \mathrm{Ni}, \mathrm{Se}$, and $\mathrm{Zr}$. They were chosen because they are in very low concentration in the orchard leaves and because their $x$-ray energies span the range of lnterest for the ${ }^{109} \mathrm{Cd}$ source.

A $\log -\log$ plot of the measured absorption coefficlents vs $x$-ray energy gave nearly a straight line. It was thus possible to get good values of the absorption coefficients of the other elements by interporation. Once the absorption coefficients were measured we could make the absorption corrections as described earlier.

The analytical data are summarized In Table 4. As can be seell, the agreement with the NBS published values is excellent. Our values and the NBS values agree to within ihe quoted uncertainties in all cases except arsenic. There is aupporting evidence from other investigator ${ }^{\prime}$ that the NBS value for arsenic may be toe high.

These results give us confidence in the capability of our system. Admittedly. orchard leaves are not the same as air filter samples, but they are similar enough to make the comparison meaningful. These are the only analyses we have performed on an absol te standard. The analyses described in the following
Table 4. Analyses of trace constiluents of NBS orchard leaves (SRM 15711.

\begin{tabular}{|c|c|c|c|}
\hline \multirow{2}{*}{$\frac{\text { Element }}{M n}$} & \multicolumn{3}{|c|}{$\begin{array}{l}\text { LLL NBS } \\
\mu \mathrm{g} \text { per gram of dry weight }\end{array}$} \\
\hline & 83 & $( \pm 8)^{\mathrm{a}}$ & $91( \pm 4)^{9}$ \\
\hline $\mathrm{Fe}$ & 283 & $( \pm 6)$ & $300( \pm 20)$ \\
\hline $\mathrm{Cu}$ & 12. & $( \pm 2)$ & $12( \pm 1)$ \\
\hline $2 n$ & 25 & $( \pm 2)$ & $25( \pm 3)$ \\
\hline As & & $( \pm 1)$ & $14\langle \pm 2\rangle$ \\
\hline $\mathrm{Br}$ & & $( \pm 1)$ & $10^{b}$ \\
\hline Rb & 11. & $\{ \pm 1\rangle$ & $12( \pm 1)$ \\
\hline Sr & 37. & $( \pm 1)$ & $37^{b}$ \\
\hline $\mathrm{Pb}$ & 43. & $( \pm 2)$ & $45( \pm 3)$ \\
\hline
\end{tabular}

a The NBS uncertainties are 20; the LLL uncertainties are $1 \sigma$ counting statistics only.

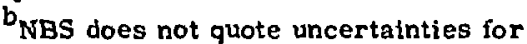
the $\mathrm{Br}$ and $\mathrm{Sr}$ values because the analyges are not certified.

sections are each relative to a single other method.

Comparison with the U.C. Davis Alpha Particle Excitation System

We compared analyses with Davis on a set of four Whatman 41 Hivol samples labelled L6, I.8, L23, and L24. These data are summarized in Table 5 . There is quite a bit of acatter, but on the average this agreement is reasonably good. If we eliminate sample L6, which apparently was giving trouble to the Davis system, the grand average ratio is 1.08 . In general, we feel that the agreement is satisfactory, considering the problems that Whatman 41 presont to a cyclotron system.

X ray Analysis Workshop

Dr. John Cooper of Battelle NW organized a sample intercomparison among a group of laboratories. A 
variety of samples, mostly air filters, were circulated among the labor: tories, analyzed by of $\mathrm{ch}$ and the data compiled and colnpired at a workshop which met from April 4-6, 1973 in Seattle.

Many difficulties arose during the intercomparison analyses, so that numbers from different laboratories are not gtrictly comparable. As a result, the workshop particlpants agreed that the actual analytical data should not be putiished.

In spite of the difficulties, the general agreement was reasonably satisfactory. Where there was reason to belleve that numbers could be compared legitimately, the deviations of the averages appeared to be less than 10\%. For example, our results are about $8 \%$ higher than those of Lawrence Berkeley Laboratory, and about 2\% lower than those of Battelle IJW on average. The standard deviation of individual values from the averages is in the range of 10 to $20 \%$.

Comparison with Neutron Activation Analysis

Mr. Milton Feldstein of the Bay Area Air Pollution Control Diatrict (BAAPCD) supplied us with a HiVol sample taken on Whatman 41 paper in San Francisco. We cut two 1 in. circles from the paper and analyzed them. The Livermore neutron activation analysis group then analyzed the samples and returned them to us for re-analysis. The $x$-ray fluorescence results were the same, within the expected uncertainties, before and after the neutron Irradiation. The results are tabulated and :ompared in Table 6 for the three elements for which both methods gave statiotically Bignlficent values. The Fe and $Z n$ values are in reasonabis agreement, but the $\mathrm{Br}$ values disagree by about $12 \%$ on average. At present we cannot explain the disagreement.

\section{Comparison with Atomlc Absorption}

Mr. Feldsteln also supplied us with a set of Beven samples which had been analyzed for $\mathrm{Cu}, \mathrm{Pb}$, and $\mathrm{Zn}$ by atomlc absorption. They had analyzed one-half of an $8 \times 10 \mathrm{in.} \mathrm{filter}$ and sent the remaining half to us. We analyzed three 1 in. circles from each of the samples.

Table 5. Comparison of Davts and LLL analyses. ${ }^{a}$

\begin{tabular}{|c|c|c|c|c|c|c|c|c|c|c|c|c|c|}
\hline & \multicolumn{8}{|c|}{$\mathrm{ng} / \mathrm{cm}^{2}$} & \multicolumn{5}{|c|}{ Retlos D/L } \\
\hline & \multicolumn{2}{|c|}{ L6 } & \multicolumn{2}{|c|}{ L.8 } & \multicolumn{2}{|c|}{1.23} & \multicolumn{2}{|c|}{1.24} & LE & L. & L23 & 1.24 & Av. \\
\hline & $L$ & $\mathrm{D}$ & L. & D & L & D & 1. & D & & & & & \\
\hline $\mathrm{Ca}$ & 590 & 754 & 3,630 & 3,884 & 3,870 & 4,412 & 2,710 & 2,583 & 1.28 & 1.07 & 1.17 & 0.95 & 1.11 \\
\hline $\mathrm{Mn}$ & - & 272 & $15 ?$ & - & 552 & - & 555 & 516 & - & - & - & 0.93 & 0.03 \\
\hline $\mathrm{Fe}$ & 1105 & 1435 & 5,761 & 5.346 & 11,346 & 10.706 & 10,105 & 0.015 & 1.30 & 0.93 & 0.94 & 0.89 & 1.02 \\
\hline $\mathbf{N i}$ & - & - & 253 & - & 540 & 778 & 328 & 543 & - & - & $1 .+4$ & 1.66 & 1.55 \\
\hline $\mathrm{Cu}$ & 253 & - & 1,465 & 1.345 & 1.428 & 1,501 & 1,754 & 2,036 & - & 0.92 & 1.05 & 1.16 & 1.04 \\
\hline $\mathrm{Zn}$ & 97 & - & 492 & 597 & 2,315 & 2,384 & 1,221 & 2,081 & - & 1.21 & 1.03 & 1.70 & 1.31 \\
\hline $\mathbf{B r}$ & 989 & 1065 & 7,167 & 6,248 & 3,738 & 4,427 & 1,386 & 827 & 1.08 & 0.87 & 1.18 & 0.60 & 0.93 \\
\hline Pb & 2381 & 4511 & 17,421 & 17,601 & 10,448 & 20.796 & 4,460 & 4,279 & 1.89 & 1.61 & 1.03 & 0.86 & 1.22 \\
\hline \multicolumn{14}{|c|}{ Average of all measured ratios $=1.13$} \\
\hline
\end{tabular}

$a_{L}$ are the Livermore analyses - D are the Davis analyses, neither set ts corrected for self-absorption. 
Table 6. Comparis on of $x$-ray fluorescence (XRF) with neutron activation analysis \{NAA\}.

\begin{tabular}{ccccc}
\hline Element & Sample & $\begin{array}{c}\text { XRF } \\
(\mathrm{ng})\end{array}$ & $\begin{array}{c}\text { NAA } \\
\text { (ng) }\end{array}$ & $\begin{array}{c}\text { NAA } \\
\text { XRF }\end{array}$ \\
\hline Fe & 3 & $2810 \pm 5 \%$ & $2880 \pm 18 \%$ & 1.02 \\
& 4 & $2790 \pm 5 \%$ & $2340 \pm 15 \%$ & 0.84 \\
$2 n$ & 3 & $2750 \pm 2 \%$ & $2550 \pm 2 \%$ & 0.93 \\
& 4 & $2700 \pm 2 \%$ & $2670 \pm 2 \%$ & 0.96 \\
$\mathrm{Br}$ & 3 & $5240 \pm 4 \%$ & $5810 \pm 3 \%$ & 1.11 \\
& 4 & $5290 \pm 3 \%$ & $6010 \pm 2 \%$ & 1.14 \\
\hline
\end{tabular}

Unfortunately these samples showed rather large variations from point to point. The $\mathrm{Cu}$ and $\mathrm{Zn}$ in particular appeared to be unevenly distributed. The $\mathrm{Pb}$ seemed to be diatributed much more uniformly.

The data are summarized in Table 7. The average ratios of atomic alborption to $x$-ray fluorescence results are:

$\mathrm{Cu}=0.89, \mathrm{Zn}=0.88$, and $\mathrm{Pb}=0.90$.

The differences between the two methods are well within the spread of individual samples, so the agreement is not unreasonable. The fact that all of the ratios are less than unity may indicate some sort of systematic error, but the uncertainties are too large to make a definite statement. It is encouraging that $\mathrm{Pb}$, the most uniformly distributed element, gives the best agreement.

\section{REPRODUCIBILITY OF MEASUREMENTS}

Two 1 in. diam circles were cut from a Whatrian 41 HiVol sample and analyzed six times over a period of two months. In these samples there were measurable amounts of $\mathrm{Fe}, \mathrm{Cu}, \mathrm{Zn}, \mathrm{Br}$, and $\mathrm{Pb}$.

The data are summarized in Table 8. In all cases the standard deviations of the measured values were less than of
Table 7. Comparison of $x$-ray fluorescence (XFF) with atomic absorption (AA).

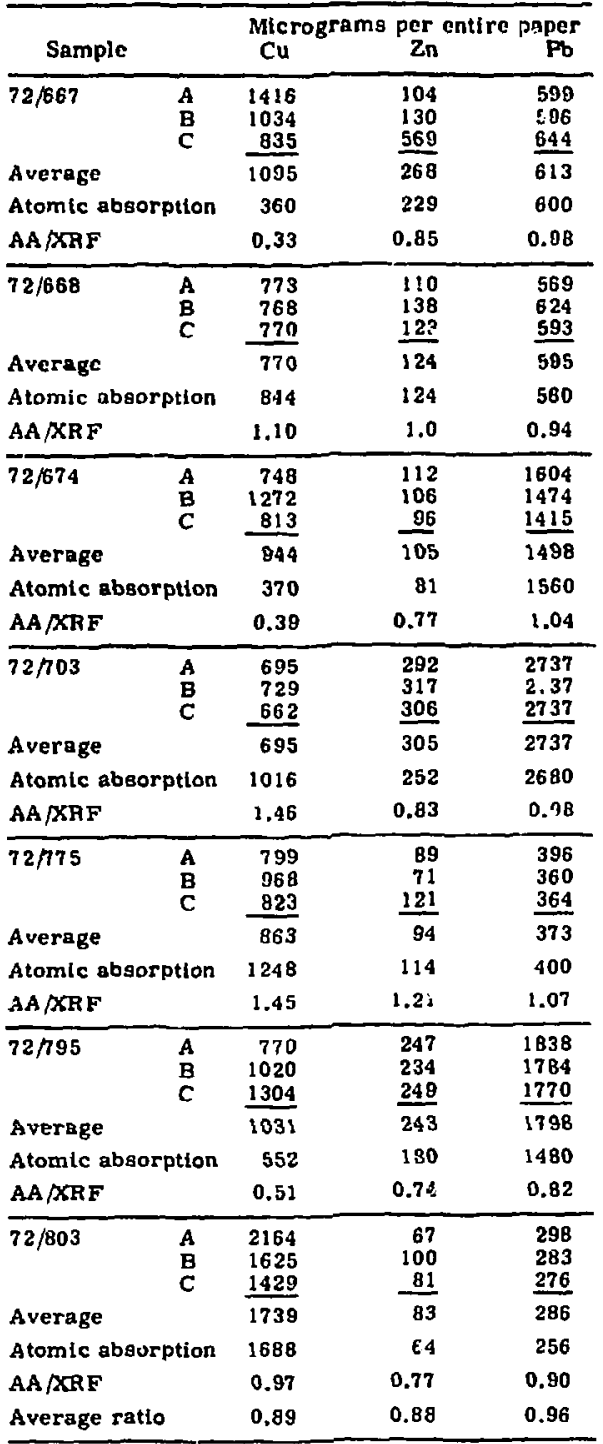

approximately equal to the statistical counting error as estimated by XRA6. This shows that the system is stable and 
thire are no unknown random variables. It appears that we may be overestimating the expected standard devlation in some cases.

\section{SOME CHARACTERISTICS OF HIVOI SAMPLEن}

Because HiVol samplers are used extensively to collect. aerosol samples on Whatman 41 it seemed useful to measure some of the characteristics of such samples. In particular, our experience with the samples used for the comparison with atomic absorption showed that the deposits were not uniform across the filter. In addition, we suspected that bromine might be lost from filter samples because some of the common chemical forms of bromine are volatile.

\section{Uniformity of Distribution}

We studied two $8 \times 10$ in. Hivol samples on Whatman 41 . With the large Lucite holder on the sample head we could measure any part of an $8 \times 10$ in. paper without cutting it. We measured nine evenly spaced 1 in. diam areas on each paper and got values for $\mathrm{Fe}, \mathrm{Cu}$, $\mathrm{Zn}, \mathrm{Br}$, and $\mathrm{Pb}$ for each area. We then calculated the ratio of each measured value to the average for that element. These ratios are displayed in Tables 9 and 10. The position of the ratios in the table corresponds roughly to the measured positions on the filter. The high $\mathrm{Br}$ value in the upper left corner of Table 9 is real. It was remeasured after the original observation. At the bottom of each table the standard deviations of the measured values are compared with the expected standard deviations calculated by XRA6.
In most cases the measured deviations aro greater than expected from the counting stetistics. Apparently there are real differences in concentrations from one part of the paper to another. The differences in these papers are not nearly as great as those in the papers used in the atomlc absorption comparison (see Table 7). This may be the result efther of differences in individual sampler units or of the nature of the aerosol sampled. These two samples were collected in Livermore whereas the atomic absorption samples were collected in Crockett.

\section{Stability of Bromine on Whatman 41}

Mr. Feldstein of the BAAPCD collected a 36-hr HiVol semple for us on Whatmen 41. It was collected in San Francisco on a rainy day, welghed in their controlled humidicy environment and sent to us. We cut six 1 in.-circles from it and

Table 8 . Consistency of measured values over a two-month period.

\begin{tabular}{lccc}
\hline Etement & HE & $\begin{array}{c}\text { Standard } \\
\text { deviation } \\
\text { of measured } \\
\text { values } \\
\text { (\%) }\end{array}$ & $\begin{array}{c}\text { Expected } \\
\text { \% standard } \\
\text { deviation } \\
\text { calculate } \\
\text { by XRA6 }\end{array}$ \\
\hline $\begin{array}{c}\text { Sample No. } 1 \\
\mathrm{Fe}\end{array}$ & 3.09 & 2.7 & 6 \\
$\mathrm{Cu}$ & 0.60 & 5.0 & 15 \\
$\mathrm{Zn}$ & 2.53 & 1.7 & 3.5 \\
$\mathrm{Br}$ & 5.04 & 1.0 & 1.5 \\
$\mathrm{~Pb}$ & 14.4 & 1.4 & 1.2
\end{tabular}

Sample No. 2

\begin{tabular}{lccc}
$\mathrm{Fe}$ & 3.06 & 4.6 & 6 \\
$\mathrm{Cu}$ & 0.61 & 9.2 & 15 \\
$\mathrm{Zn}$ & 2.46 & 3.3 & 3.5 \\
$\mathrm{Br}$ & 4.94 & 1.0 & 1.5 \\
$\mathrm{~Pb}$ & 14.1 & 1.4 & 1.2 \\
\hline
\end{tabular}


T'able 9. Study of uniformity of distribution on a Hivol sample.

\begin{tabular}{l|l|l|l|}
\hline \multicolumn{2}{|c|}{ Sampie No. 5759} & & \\
$\mathrm{Fe}$ & 0.95 & 1.04 & 0.98 \\
$\mathrm{Cu}$ & 1.12 & 0.90 & 0.87 \\
$\mathrm{Zn}$ & 0.98 & 1.12 & 0.94 \\
$\mathrm{Br}$ & 2.98 & 0.77 & 0.67 \\
$\mathrm{~Pb}$ & 0.99 & 1.07 & 0.95 \\
\hline $\mathrm{Fe}$ & 0.98 & 1.09 & 1.00 \\
$\mathrm{Cu}$ & 0.90 & 0.73 & 1.25 \\
$\mathrm{Zn}$ & 1.04 & 1.04 & 0.94 \\
$\mathrm{Br}$ & 0.70 & 0.79 & 0.83 \\
$\mathrm{~Pb}$ & 0.97 & 1.02 & 1.06 \\
\hline $\mathrm{Fe}$ & 0.92 & 1.07 & 0.97 \\
$\mathrm{Cu}$ & 0.96 & 1.16 & 1.12 \\
$\mathrm{Zn}$ & 0.92 & 1.08 & 0.95 \\
$\mathrm{Br}$ & 0.80 & 0.76 & 0.70 \\
$\mathrm{~Pb}$ & 1.02 & 0.98 & 0.94 \\
\hline $\mathrm{AbOv}$
\end{tabular}

Above values are ratios of each individual measurement to the average value of all nine measurements.

\begin{tabular}{ccc} 
Element & $\begin{array}{c}\text { Measured } \sigma \\
(\%)\end{array}$ & $\begin{array}{c}\text { Expected } \sigma \\
(\%)\end{array}$ \\
$\mathrm{Fe}$ & 5.5 & 1.3 \\
$\mathrm{Cu}$ & 17 & 19 \\
$\mathrm{Zn}$ & 7.0 & 9 \\
$\mathrm{Br}$ & 74 & 4.5 \\
$\mathrm{~Pb}$ & 4.7 & 2.5 \\
\hline
\end{tabular}

analyzed them for $\mathrm{Br}$ upon receipt (about $24 \mathrm{hr}$ after the end of the collection time).

Two of the samples were allowed to stand in petri dishes under ordinary laboratory lighting (fluorescent fixtures) for several months, two were kept in vacuum at a few inicrons pressure for $18 \mathrm{hr}$, and two were sent to the reactor for neutron activation analysis,

None of the samples lost nieasurable amounts of Eir; in this sample, at least,
Table 10. Study of uniformity of distribution on a HiVol sample.

\begin{tabular}{l|l|l|l|}
\hline \multicolumn{3}{|c|}{ Sarnple No. 5485} & \\
$\mathrm{Fe}$ & 0.99 & 1.08 & 0.96 \\
$\mathrm{Cu}$ & 0.85 & 0.92 & 1.26 \\
$\mathrm{Zn}$ & 1.03 & 1.12 & 0.87 \\
$\mathrm{Er}$ & 0.91 & 1.04 & 1.02 \\
$\mathrm{~Pb}$ & 0.96 & 1.02 & 1.00 \\
\hline $\mathrm{Fe}$ & 0.97 & 1.04 & 0.97 \\
$\mathrm{Cu}$ & 0.86 & 1.03 & 0.70 \\
$\mathrm{Zn}$ & 0.97 & 1.03 & 0.93 \\
$\mathrm{Br}$ & 0.98 & 1.04 & 0.97 \\
$\mathrm{~Pb}$ & 0.98 & 1.03 & 0.98 \\
\hline $\mathrm{Fe}$ & 0.94 & 1.06 & 1.00 \\
$\mathrm{Cu}$ & 1.09 & 1.15 & 1.15 \\
$\mathrm{Zn}$ & 0.95 & 1.06 & 1.04 \\
$\mathrm{Br}$ & 0.96 & 1.07 & 1.02 \\
$\mathrm{~Pb}$ & 0.96 & 1.06 & 1.01 \\
\hline $\mathrm{AbOv}$
\end{tabular}

Above values are ratlos of individual measurement to the average value of all nine measurements.

\begin{tabular}{ccc} 
Element & $\begin{array}{c}\text { Measured } \sigma \\
(\%)\end{array}$ & $\begin{array}{c}\text { Expected } \sigma \\
(\%)\end{array}$ \\
$\mathrm{Fe}$ & 4.4 & 1.2 \\
$\mathrm{Cu}$ & 17 & 9 \\
$\mathrm{Zn}$ & 7.3 & 5.5 \\
$\mathrm{Br}$ & 4.7 & 1.2 \\
$\mathrm{Fb}$ & 2.9 & 1.2 \\
\hline
\end{tabular}

the amount of $\mathrm{Br}$ present appears to be quite stable. This sample may not be a typical air filter sample because of having been collected on a rainy day. The experiment should be repeated with samples collected under a variety of conditions.

BAY AREA AIR POLLUTION CONTROL DISTRICT SAMPLES

As a test of the system's ability to operate on a routine basis, we analyzed 
71 HiVol samples on Whatman 41 paper. The Bay Area Air Pollution Conirol District very kindly made these avallable to us. They were all of the existing Livermore samples collected by the District over the past several years.

We have not yet analyzed the data in detail, wut some preliminary findings are:

1) The system works well on a routine basis. Running a large number of samples presented no problem.

2) As expected, the Livermore samples contain a limited set of elements. All samples contained measureable amount of $\mathrm{Cl}, \mathrm{K}, \mathrm{Ca}$, $\mathrm{Fe}, \mathrm{Cu}, \mathrm{Zn}, \mathrm{Br}$, and $\mathrm{Pb}$. One or more of the elements $\mathrm{Tl}, \mathrm{V}, \mathrm{Nl}$, and $\mathrm{Sr}$ showed up in a few samples.
Table 11. Concentration ranges of elements found in Livermore air samples.

\begin{tabular}{ccc}
\hline Element & $\begin{array}{c}\text { Concentration range } \\
\left(\mu \mathrm{g} / \mathrm{m}^{3}\right)\end{array}$ \\
\hline $\mathrm{Cl}$ & 1 & -20 \\
$\mathrm{~K}$ & $0.2-1.2$ \\
$\mathrm{Ca}$ & $0.5-2.7$ \\
$\mathrm{Ti}$ & $<0.01-0.3$ \\
$\mathrm{~V}$ & $<0.01-0.04$ \\
$\mathrm{Fe}$ & $0.4-4$ \\
$\mathrm{Ni}$ & $<0.01-0.03$ \\
$\mathrm{Cu}$ & $0.03-0.5$ \\
$\mathrm{Zn}$ & $0.03-0.3$ \\
$\mathrm{Br}$ & $0.07-0.7$ \\
$\mathrm{Sr}$ & $<0.004-0.03$ \\
$\mathrm{~Pb}$ & $0.3-2$ \\
\hline
\end{tabular}

The approximate concentration ranges are listed in Table 11.

\section{Suggested Improvements for Future Systems}

In this section we will discuss several possible improvements in $x$-ray analysis systems. Some of thesi will allow lower trace element detectabilities than those reported in Table 2, while others will deal with automation or data handling. The discussion is divided into four sections:
A) improvements in the present design,
B) other methods of $x$-ray excitation,
C) peripheral equipment improvements, and D) commercial equipment.

\section{MODIFICATION OF THE PRESENT DESIGN}

One of the simplest and most productive improvements would be the addition of an automatic sample changer to our system. Automation would allow the system to operate $24 \mathrm{hr} / \mathrm{d}$, which would at least triple the output relative to a $40-\mathrm{hr}$ work week. Automating the system would make necessary "on-line" data reduction. That means solving the matrix interference equation in the small compuier instead of using a large separate computer. This can be done on our system by adding 8K of memory. The additional memory would also control the automated sample changer.

Another simple and direct improvement is achieved by increasing the exciter source strengths. The limit cn source strength is set by the maximum information rate acceptable by the analyzer. As the source strength is increased the detector counting rate and system "dead 
time" also Increases. At some source strength the rate of information storage will reach a maximum. Any further increase in count rate will actually decrease the amount of information stored. Increasing the ${ }^{109} \mathrm{Cd}$ source strength to $30 \mathrm{mCi}$, and the ${ }^{55} \mathrm{Fe}$ strength to $500 \mathrm{inCl}$ would bring the system to near optimum. The counting time would be reduced by factors of 2 and 40 respectively, without changing the statistical uncertainties in the analytical results. In practice the specific activity of commercially available ${ }^{55} \mathrm{Fe}$ and source self-absorption will limit the increase in this source strength to something less than 40 .

A third type of improvement is any change which decreases the background relative to the signal strength. The basic limitation on detectability is the signalto-background ratio; any improvement in this ratio will lower detection limits.

We will discuss four ways of decreasing the background: 1) removal of air,

2) changes in the sample collection matrix, 3) detector collimation, and 4) changes in geometry.

Removal of Air from the Sample Region

In the present system the amount of backscatter from air is approximately equal to that from a Whatman 41 sample. Therefore, the back ;round could be reduced by a factor ol $?$ if the system were evacuated or filled with helium. (The entire factor of 2 is not realizable since the presence of a vacuum enclosure itself will produce some scattering, hence increase the background.) Removal of air has the further advantage of reducing low energy x-ray absorption.
Changes in the Sample Collection Matrix

Air samples are collected on various types of filter media which vary in their mass per unit area. Some improvement can be realized in the signal to background ratio if filters of less mass per unit area are used. Whatman 41 averages about $9 \mathrm{mg} / \mathrm{cm}^{2}$. Millipore is about $5 \mathrm{mg} / \mathrm{cm}^{2}$. and Nucleopore is near $1 \mathrm{mg} / \mathrm{cm}^{2}$. If a filter medium with a mass per unit area one-tenth that of Whatman 41 were used, then the backscatter from the filter would be reduced by a factor of 10 . No reduction in signal strength would occur. However, this gain is realized only if the air has been removed.

The potential factor of 10 in background reduction is aignificant, and would appear to be a very worthwhile goal.

\section{Detector Collimation}

Part of the background continuum is the result of incomplete charge collection in the Si(Li) detector. Part of the charge produced by $x$ rays absorbed near the edge of the detector may escape sideways. This charge loss mechanism can be reduced by severely collimating the detector. Our detector has an area of $80 \mathrm{~mm}^{2}(1.0 \mathrm{~cm}$ diam). Collimation of this area down to $20 \mathrm{~mm}^{2}$ decreased the background by about two. It also reduced the count rate by four, requiring a fourfold increase in the exciter strength to maintain the same sensitivity.

\section{Changes in Geometry}

Previously we mentioned that a $90^{\circ}$ geometry has about one-half as much. Compton scattering as a $180^{\circ}$ gecrnetry. Thus, change to a $90^{\circ}$ geometry could 
reduce the background by nearly a factor of two. However, this geometry requires such a large increase in the source strength that it is not practical for radioisotope excited system.

To summarize the possible improvements in signal-to-background ratio: we can gain a factor of two by evacuating the system, possibly a factor of ten by changing the sample collection matrix and a factor of two by collimating the detector. Thus, improvement could be at best a factor of 40 , most of which is the result of the matrix mass reduction. Trace element detection limits improve as the square root of the signal-tobackground ratio, so the above changes could improve detectabilities by about a factor of $\mathrm{six}$.

Combiring this improvement with optimization of the count rate could improve the system sensitivity by nearly an order of magnitude. It should be noted that all of these improvements combined would require an increase in exciter strength of about ten also.

\section{OTHER METHODS OF X-RAY EXCITATION}

$X$ rays can be excited by protons, alpha particles, or heavy ions as well by photons. J. Cooper ${ }^{3}$ has made a comparison of the relative detectabilities achieved by particles vs. phstons. Protons appear to be better than either alpha particles or Leavy ions, but the choice between urotons and photons is not clear. The detectability limits are similar but there are many other factors to be considered, such as types of filter media (which affect more severely the proton limits than the photon limits), which elements are of most interest, avallability cf accelerators, realistic cost per sample, etc. We will not make any further comments about particle excitation, but rather in this section we will discuss the use of $x$-ray tube excitation.

In an $x$-ray tube an electron beam bombards a metallic anode producing both the characteristic $x$ rays of the anode and a bremsstrahlung (continuous) energy spectrum. To effectively compete with the isotopic source systems, the bremsstrahlung must be removed. This car. be done by using a transmission anode, which tilters most of the continuous radiation but transmite the characteristic $x$ rays, Somewhat better results are obtained by using a secondary fluorescer. In this approach the primary $x$ rays fluoresce a secondary target made of a lower $Z$ element. The secondary $x$ rays are then the exciting source for the sample. If the geometry is very ce: efully arranged, secondary fluorescence can produce spectra nearly as clean as isotopic sources.

The advantages of tube excitation are: the inter $r_{i}$ ity is controllable, thus the count rate can always be optimized; the use of a variety of secondary fluorescers allows the exciting energy to be more easily optimized to a partinular range of elements; the intensities are high enough that $90^{\circ}$ geometry can be used. In short, the basic advantage is that the source is controllable. However, this flexibility necessitates a separate calibration for each current, voltage and secondary exciter setting chosen.

In our opinion the advantages outweigh tue disadvantages, so we would probably 
design any future system around an $x$-ray tube. A tube excited system could be automated almost as easily as one using a radioactive source.

\section{PERIPHERAL EQUIPMFNT} IMPROVEMENT

In addition to the improvements expected to take place in the fuorescence techniques, developments will also occur in small computer based systems. Based upon evidence gained from several prototype systems assembled here, which carry out data analysis not unlike that required in trace element analyses, these systems in the future will have a computing power not limited to the size of the memory buffer. This means not only that the kind of matrix calculations required will be done with the small computer, but also that the background subtraction and peak integration software routines will become more aophisticated.

The result of this increase in computing power will be more accurate data analysis. In addition, programming which is now mostly done in machine language (very time consuming) will be done in FORTRAN, a much simpler and more universally used programming language. Within two to three years, such amall computing systems will be purchasable for the same investment cost as small computer systems now having much less capability. The computer will control any automated sample changer as well as carry out all necessary calculations and data storage in a time not significantly longer than now required.

\section{COMMERCLAL EQUIPMENT}

Suppose an organization such as the ARB decided it would like to purchase an $\mathrm{X}$-ray nuorescence analysis system for monitoring air quality. The question arises, is a suitable system available commercially? in brief, the answer is no.

We have made a careful survey of the companies which currently supply such $x$-ray fuorescence analysis systems. Although all of the components required for a state-of-the-art $x$-ray nuorescence system are manufactured, there is no single company which manufactures and services a complete system with all of the desired characteristics. No attempt will be made here to detail or compare the various equipment and options available since such a discussion would be a significant report in itself. Suffice it to say that if an optimum system were assembled today it would necessarily be a composite of components from several different companies. These components might not be directly connectable to each other, in which case they would require special interfaces. These would be oneof-a-kind, expensive, and would require time to procure.

At first giance sales brochures from any of the companies attempt to convince the prospectlve user that they offer "just what the user needs," that "their" method does $X$-ray fluorescence the "best" possible way. The literature is replete with phrases such as "ideal excitation," "highest resolution," "ease of operation," "computer compatible," and many others. These phrases may not mean the same thing to the reader of the brochures as 
they did to the writer. When any large laboratory or compeny purchases equipment to do $x$-ray nuorescence analysis, they can often call upon a breadth of inhouse talents to customize their purchase. A smaller laboratery or group must accept what is delivered as is.

In conclusion then, the optimum system for the analysis of trace elements in aerosol type samples by $x$-ray nuorescence is not yet commercially avallable, but may be in two or three years. If and when a system is purchased, the user must assure himself that it will deliver meaningful results consistent with his particular needs.

\section{Summary and Conclusions}

We have assembled an $x$-ray fluorescence system to determine the trace element composition of air filter samples. The system consists of a set of three intercnangeable radioisotope exciter sources, a Si(Li) detector, and a computer based pulse height anaiyser and data storage system. The nondispersive, energy sensitive $S i(L i)$ detector and its associated electronics sort the $x$-rays according tc energy. The system operates without physically separating the $x$ rays according tc wavelength.

We have tested the analytical capability of the system for samples collected on a variety of filter media, e.g. Whatman 41 filter paper, IPC paper, glass fiber filter paper, Millipore and Nucleopore. We concentrated on the analysis of samples on Whatman 41 paper because it is a reasonably good medium in wide general use.

For samples on Whatman 41 , counted for $1000 \mathrm{sec}$, the detectability limits range from 10 to $100 \mathrm{ng} / \mathrm{cm}^{2}$ for all elements heavier than potassium $(Z=19)$. For lighter elements, absorption effects are large, sensitivities are smaller and the detection limits are correspondingly poorer. We have made only a few measurements in the region between ruthenium $(Z=44)$ and ytterbium $(z=70)$ but there is no reason to believe that quantitative measurements cannot be made throughout this region. Therefore, the useful quantitative range for this system extends from calcium $(Z=20)$ to uranium $(Z=92)$. Detectabilities of 10 to $100 \mathrm{ng} / \mathrm{cm}^{2}$ correspond to concentrations in air of 3 to $30 \mathrm{ng} / \mathrm{m}^{3}$ in a typical filter sample collected over a $24-\mathrm{hr}$ period.

The reproducibility of measurements is usually better than $5 \%$ and ia limited by counting statistics. The accuracy on an absolute basis is probably within $\pm 10 \%$. This value is based on the differences observed for various kinds of absolute standards and on the results of comparisons with other analytical techniques. The uncertainties caused by present sampling systems are generally greater than $10 \%$. Thus, improvements in sampling methods are vital if air pollution monitoring is to become truly quantitative.

In conclusion, the radioisotope source XRFA system is useful for the 
determination of trace elements in air particula te samples collected on a light matrix of low atomic number. The method is completely non-destructive to the sample, the analysis time is reasonably short, no sample preparation is required, the system is simple to operate, and the accuracy obtained is better than $10 \%$.
Automated, a similar syatem could perform trace element analyses on thousands of air fliter samples per year almost without attention. The quantltative information obtained would be extremely useful both in monitoring alr pollution levels and In formulating and enforcing air pollution requirements.

\section{References}

1. R. Glauque, Lawrence Livermore Laboratory, Rept. UCRL-18292, Rev, (1968).

2. K. Heydorn and W. Iada, Anal. Chem. 44, 2313 (1972).

3. J. Cooper, Nucl, Instr. Methods, (in press, 1973). 


\section{Appendix A}

DETAILED DESCRIPTION OF

ELECTRONICS SYSTEM AND COSTS

Figure A-1 shows a logic block diagram of the system. The left side shows the detector and supporting electronlcs. The right side includes the computer and various input/output (I/O) peripherals.

$X$ rays from the fluoresced sample deposit energy into the Si(Li) detector. The charge deposited is processed first by a charge sensitive preamplifier which routes the pulses to a linear amplifier for shaping and also to a pile-up rejection circuit. The pile-up rejection circuit performs two essential tasks. It prevents pulse summing and it corrects an internal clock for the time actially spent processing pulses. At higher count rates pulses begin to come so frequeutly that a second pulse may occur before the amplifier has completely finished processing the previous pulse. The second pulse height would not be sorter correctly if it were allowed through the system, hence this pulse is rejected. Pile-up rejection is very necessary at high count rates $>2000 \mathrm{c} / \mathrm{sec})$ in order to avoid spectrum degradation.

At low count rates slock time or the actual elapsed time is essentially the same as the "live" or pre-set analysis time. At high count rates the elapsed time will be much longer than the preset "live" analysis time. The latter is increased by an amount approximately
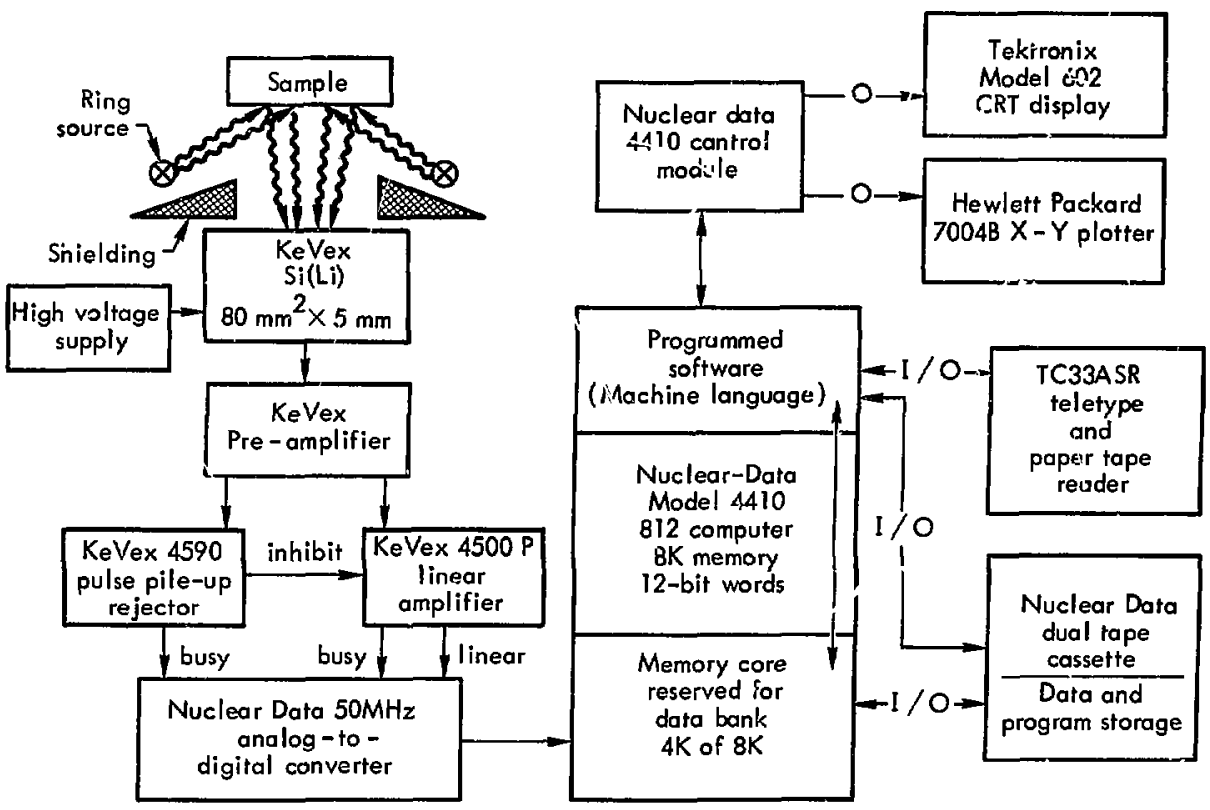

Fig. A-1. Schematic diagram of the radioisotope $x$-ray analysis electronics system. 
equal to the product of the clock time and the percent of real time spent by the amplifier in shaping the pulses (dead time). Live time correction and pulse pile-up rejection are both necessary to insure consistent and quantitatively accurate results independent of the counting rate and/or analysis time selected.

The analog-to-digital converter receives the analog pulse height Information froin the amplifier and convorts it to digital logic levels compatible with a digital computer. The spectrum recorded by the energy gensitive Si(Li) detector is stored in digital form and continually updated during analysis in part of the computer memory - the data banis.

From this point on, control of the experimental information is exercised through pre-wired functions on the program control module (16 different functions) or through appropriaie instructions entered via the teletype console. The data being accumulated $\mathrm{r}_{\text {a }}$ ay be seen (as it is being updated in the memory bank or after the analysis is completed) on a CRT video display. AccumuLated data may be plotted in either a linear or logarithmic mode on an $X-Y$ plotter.

The computer has memory core alloted for both a data bank ( $4 \mathrm{~K}-12$ bit words) and a computer program or software bank ( $4 \mathrm{~K}-12$ bit words). The I/O peripherals both transmit and receive from either the $4 \mathrm{~K}$ data bank or from the $4 \mathrm{~K}$ software bank. The software or programming used in this computer is that developed by Nuclear Data, Inc. and slightly modified by our own programmers. It is sirnilar to makhine language; but it is not compatible with FORTRAN or any other higher level programming language.
A typical sample analys is routine might occur as follows. The counting time is entered by typing the desired time on the teletype console. This establishes the counting time for all subsequent analyses or until changed. One of two possible 1024 channel memory groups is chosen for data storage. Accumulation of the $x$-ray spectrum begins when one of 16 pre-wired control buttons is depressed. $X$-ray pulse height information from the sample and detector can now pass through the electronics to the memory bank. At the end of data accumulation the operator may display, plot, store, transfer, or modify this data via the teletype and control mocule.

During data accumulation, data stored in the other memory group, e.g. from a previous sample analysis, may be rperated on by the computer. That is, it may be displayed, plotted, transferred to magreicic tape cassette or in some way modified by cor iputer program routines in the 415 software bank. Also simultaneously with data storage in one group. $t i=$ to 16 pre-selected integrated areas (wind ow regions in the spec'rum) may be obtained from the other group via softurare coding in mimory. Depressing anothen of the 16 pre-wired control buttons initlates this option and makes the teletype console print out the data.

Although we did not dievelop an automated sample changer, such al changer could be interfaced to this system very easily. Changing from a manual to an automatic mode would be done in seconds via the control module or the teletype console.

Table A-1 contains a complete list of the equipment used in this work along with current market prices. 
Table A-1. Equipment cost.

\begin{tabular}{|c|c|c|}
\hline Item No. & Description & $\operatorname{Cost}^{\mathrm{a}}$ \\
\hline 1 & $\begin{array}{l}\text { Nuclear Data } 4410 \text { System consisting of: } \\
\text { a) ND } 812 \text { Computer } 8 \mathrm{~K} \text { (12 bit word) memory } \\
\text { b) Control Module } \\
\text { c) } 50 \mathrm{MHz} \text { Analogue to Digiral Converter }\end{array}$ & 15,120 \\
\hline 2 & Nuclear Data Dual Tape Cassette, 3 Cassettes incl'd & 3,600 \\
\hline 3 & Teletype Model TC33ASR with paper punch/reader & 1,200 \\
\hline 4 & Tektronix Model 602 Display Scope & 1,050 \\
\hline $5^{b}$ & Hewlett Packard Model 7004B XY Plotter & 2,275 \\
\hline$=$ & 5-foot Electronics rack with wheels, AC plug strip & 150 \\
\hline 7 & $\begin{array}{l}\text { Kevex Detector Model } 3000 \text { Mark AA }\left(80 \mathrm{~mm}^{2} \mathrm{Si}(\mathrm{Li})\right. \\
\text { detector) with } 31 \text { liter dewar }\end{array}$ & 6,400 \\
\hline 8 & KeVex Amplifier Model 4500P (Pulsed Optical Feedback) & 1,050 \\
\hline 9 & $\begin{array}{l}\text { Kevex Pulse Pile Up Rejector Model } 4590 \\
\text { Live time correction included }\end{array}$ & 895 \\
\hline $10^{b}$ & KeVex Detector High Voltage Supply; Vacuum monitor & 550 \\
\hline 11 & 12 bin width NIMBIN with power supply & 750 \\
\hline 12 & $\begin{array}{l}\text { Parts and Mechanical Engineering for source exciter } \\
\text { holder and sample support system }\end{array}$ & 700 \\
\hline 13 & $\begin{array}{l}15 \mathrm{mCi} \text { Cd Radioactive Source } \\
\text { (good for two years usage) } \\
15 \mathrm{mCi} 55 \mathrm{Fe} \text { Radioactive Source } \\
\text { (good for four years usage) }\end{array}$ & 2,000 \\
\hline & Total Costs & $\$ 35,800$ \\
\hline
\end{tabular}

These are current market costs as of March 31, 1973. We paid somewhat less for this equipment as most of it is from two to three yeara old.

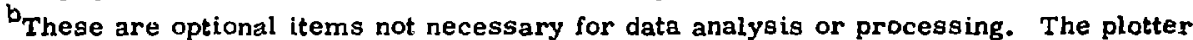
is desirable for graphical visualization and records of data. The high voltage supply in our system was replaced by three $300 \mathrm{~V}$ batteries. 


\section{Appendix B}

\section{X-RAY ABSORPTION CORRECTIONS}

\section{Effects of Sample Dlameter}

In order to make corrections for absorption, it is necessary to know the absorption coefficient for the radiation in the sample material. The absorption coefficient, $a$, is defined by the equation

$$
I=I_{0} e^{-a D}
$$

where

$$
\begin{aligned}
& I_{0} \text { is the measured intensity of an } \\
& x \text { ray with no absorber, } \\
& \text { I is the measured intensity after } \\
& \text { the } x \text { ray has passed tnrough a } \\
& \text { thickness D of the absorbing } \\
& \text { material. }
\end{aligned}
$$

In our aystem, a includes the absorption of woih the exciting and emitted $x$ rays.

We can thus measure the absorption coeificient for any element in a futer sample by measuring the counts per second of a sample of the element with and without an intervening piece of filier paper.

The absorption calculations appeared to be perfectly straightforward until we started to measure thick samples of single elements as a check on our thin standards. With thick samples the absorption coefficient is obviously extremely important. We found that the thick standards and the thin standards disagreed by amounts far beyond our expected experimental errors, and in an apparent'y random way. The trou'ble was finally triced to the absorption coefficient. The accompanying schematic drawing of cur system shows where the probiem lies (Fig, B-1),
If line $A$ is the path of the exclting radiation and 1 ine $B$ is the path of the emitted $X$-ray, the lengtt: of $A$ within the sample is considerably lorger than the length of $B$ within the Bample. Since the absorption deperds on the product of the absorption coefficient and the path lengths, we cannot simply add the two absorption coefficients (which is effectively what we had done previously). To further complicate the matter, the relative path lengths are not equal and not constant for a d'stributed sample, but depend on the position of the atom being excited. If the lines $A^{\prime}$ and $B^{\prime}$ are aubstituted for $A$ and $B$ this becomes obvious. Thus, the weighting factors to

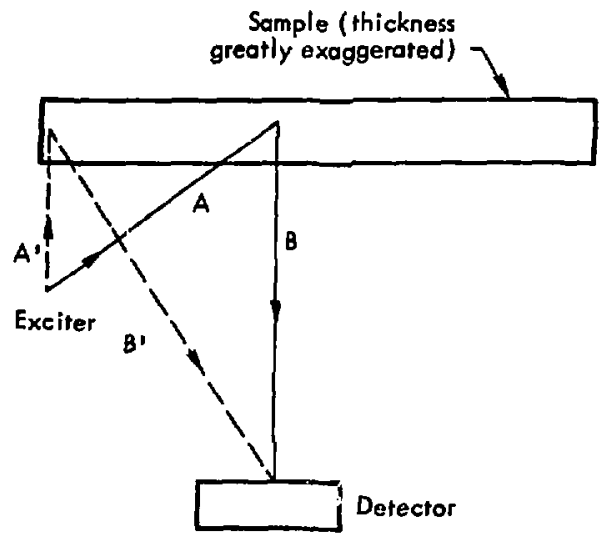

Fig. B-1. Schematic drawing of the $x$-ray fluorescence system showing the geometry used for absorption calculations. Since the relative path lengthis are not equal or constant for a uniformly distributed sample, the weighting factors to be applied to the two absorptic 7 coefficients must be fcund by averaging over all possible puiths. 
be applied to the two absorption coefficents must be found by averaging over all possible paths.

Fortunate? $y$ a series of experiments showed that for a given diameter sample the weighting factors are nearly independent of energy. That is, the effective absorption coefficient, $a$, can be represented as

$$
a=c_{1} a_{1}+c_{2} a_{2}
$$

where

$a_{1}=$ the absorption coefficient for the exciting radiation in the sample material,

$a_{2}=$ the absorption coefficient for the emitted $x$-ray in the sample material $\left(a_{1}\right.$ and $a_{2}$ are obtained from published compilations).

$c_{1}$ and $c_{2}$ are the experimentally determined weighting factors.

The constants must be experimentally determined for each sample diameter.

With these relationships available it becomes possible to use thick standards as well as thin standards for calibration. This is particularly helpful when trying to measure low energy $x$ rays where almost any sample is thick enough tc cause some absorption.

These studies also point out that one must be careful in measuring absorption coefficients for filter samples. The absorption standard must be the same diameter as the samF'? being measured or the effective absorption coefficient will be wro.'g.

\section{Absorption Corrections in Samples}

Consider a sample collected on a filter paper and distributed throughout

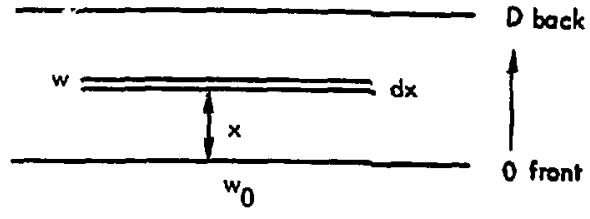

Fig. B-2. Schematic drawing defining terms used in computing absorption corrections.

the volume of the paper in some manner (Fig. B-2).

Define the following terms:

$D=$ total thickness of paper. For convenience we will express thickness in $\mathrm{mg} / \mathrm{cm}^{2}$ instead of cm.

$x=$ distance from collecting face, $\mathrm{mg} / \mathrm{cm}^{2}$.

$w=$ concentration of collected element in units of $\mu \mathrm{g}$ of element per unit thickness.

$w_{0}=$ concentration at front face of futer. For lack of better information, assume that $w$ decreases exponentially with depth:

$$
w=w_{0} e^{-b x} .
$$

where $b$ is the distribution coefficient in units of $\mathrm{cm}^{2} / \mathrm{mg}$. The total mass, $M$ of an element in the paper in $\mu \mathrm{g}$ is then

$$
\begin{aligned}
M=\int_{0}^{D} w d x & =\int_{0}^{D} w_{0} e^{-b x} d x \\
& =\frac{w_{0}}{b}\left[1-e^{-b D}\right] .
\end{aligned}
$$

Now corisider the $x$-ray signal from such a sample.

Let:

$$
\begin{aligned}
I & =\text { measured } \mathrm{x}-\mathrm{x} \text {-ay } \mathrm{signai} \text { in } \mathrm{cps} \\
\mathbf{k} & =\text { calibration factor, cprs } / \mu \mathrm{g}
\end{aligned}
$$


$a=$ effective $x$-ray absorption coefficient in $\mathrm{cm}^{2} / \mathrm{mg}$. This includes the absorption of both the exciitng $x$ ray and the emitted $x$ ray. It also inciudes the angle effects discussed er.rlier.

The aignal from the layer $\mathrm{dx}$ at depth $\mathrm{x}$ with concentration $w$ is

$$
d \mathrm{l}=\mathrm{kw} \mathrm{e}^{-\mathrm{ax}} \mathrm{dx} .
$$

The term $e^{-a x}$ is the attenuation due to absorption by the thickness $x$ of filter between the layer $\mathrm{dx}$ and the detector. Substituting Eq. ( $B-1)$ into (B-3) we have

$$
d I=k w_{0} e^{-b x} e^{-a x} d x,
$$

then

$$
I=k w_{0} \int_{0}^{D} e^{-(b+a) x} d x
$$

and finally

$$
I=\frac{k w_{0}}{(b+a)}\left[1-(e)^{-(b+a) D}\right]
$$

Combining this with the expression for M (Eq. B-2) we get

$$
M=\frac{I(b+a)\left(1-e^{-b D}\right)}{k b\left[1-e^{-(b+a) D}\right]} .
$$

For a sample with no absorption, the relation between $M$ and $I$ is, of course, simply

$$
M=I / k \text {. }
$$

Inus, wr: can con er the remainder of the expression a vorrection fictor to be applied to samples "."h absorption.

$$
C=\frac{(b+a)(}{b[1-} \frac{\left.-e^{-b D}\right)}{(b+a) D}
$$

Limiting cases-Two limiting cases may be considered, $a=0$ and $b \gg a$. If $A=0$, there is no absorption and $C$ becomes unity, as would be expected. If $b \gg a$, the two exponential terms become equal and the exprension reduces to

$$
C=\frac{b+a}{b}=1+\frac{a}{b} .
$$

For Whatman 41 paper $D$ is $\sim 9 \mathrm{mg} / \mathrm{cm}^{2}$, so if $b$ is greater than $0.3, e^{-b D}$ is less than 0.5 and the above expression is correct to better than 5\% regardless of the value of $a$.

\section{Determination of $a$ and $b$ - In order} to use the absorption correction we must have values for $a$ and $b$. The absorption coefficient, $a$, for any element in filter paper is easily measured by measuring the attenuation of the signal from a sample of the element by a piece of filter paper of known thickness. In fact, if necessary, the absorption by the sample itself can be measured. This might be necessary in the case of a heavily loaded sample where there is appreciable absorption by the collected sample material as'well as by the silter paper itself.

The measurement of the distribution coefficient, $b$, is somewhat more difficult. The exponential form of the distribution is an assumption, so b may not even be an adequate description of the distribution. Some measure of the distribution of the sample in the filter can be obtained by measuring the back side of the filter as well as the front side. If all of the sample is on the front, the back to front counting ratio will be just equal to the attenuation caused by one 
thickness of fllter paper. If the sample Is uniformly distributed, the front and back counting rates will be equal. We have measured front to back ratios for a number of HiVol samples on Whatman 41 and the ratios ordinarily do fall between the two extremes.

Assuming the exponential distribution to hold, the expression for the signal measured from the back side of the paper is

$$
\begin{aligned}
I_{b} & =k w_{0} \int_{0}^{D} e^{-b x} e^{-a(D-x)} d x \quad(B-11) \\
& =\frac{k w_{0} e^{-a D}}{b-a}\left[1-e^{-(b-a) D}\right] . \quad(B-12)
\end{aligned}
$$

The ratio of front tc back counting rates is, thus

$$
\begin{aligned}
R=\frac{I}{I_{b}}= & \frac{(b-a) e^{a D}}{b+a} \\
& \times\left[\frac{1-e^{-(b+a) D}}{1-e^{-(b-a) D}}\right] .
\end{aligned}
$$

This is a cumbersome expression to evaluate for $b$. In the case where $b$ is considerably greater than $a$, however, the numerator and denominator in the square brackets become equal and we can solve for b:

$$
b=\frac{-\left(R+e^{a D}\right) a}{\left(R-e^{a D}\right)} .
$$

With the HiVol filters mentioned above we get quite variable results for $b$, but for most samples and most elements, the values seem to average near 0.5. This corresponds to a half-thickness for filtration of $1.4 \mathrm{mg} / \mathrm{cm}^{2}$, which is not completely unreasonable. It means that a plece of Whatman 41 is 6 half-thicknesses thick, implying a collection efficiency of greater than $98 \%$. Thus, we have chosen to use a b value of 0.5 for all elements except chlorine for Whatman 41 HiVol samples. Chlorine seems to behave differently. Its distribution is more nearly uniform through the paper. The $b$ values for chlorine range from zero (corresponding to unlform distribution), to about 0.2 .

Table 3 lists the absorption correctlon factors we have used for Whatman 41 Hivol samples. These were calculated using measured values $a$, a value of $b$ of 0.5 for all elements but chlorine, for which we used 0.1 , and an assumed paper thickness of $8.5 \mathrm{mg} / \mathrm{cm}^{2}$. The table shows that the corrections for the ${ }^{109} \mathrm{Cd}$ source are nearly negligible in most cases, so our uncertainty in the b value is not important to the precision of our results. For the ${ }^{55} \mathrm{Fe}$ source, however, the corrections can be quite large. This is the result of two factors the low energy of the $x$ rays being measured and the absorption of the exciting radiation itself. Thus, the uncertainty in the distribution adds appreciably to the uncertainty in the results for the low $z$ elements.

\section{Absorption Calculations for Uniform} Distribution-In two situations we used a uniform distribution, e.g. our "infinitely thick" standards and our freeze-dried filter paper standards.

If we integrate Eq. (B-3) with w constant (uniforrn distribution) we get

$$
I=\frac{k w}{a}\left(1-e^{-a D}\right) \text {. }
$$


For this case, $M=W D$, and

$$
M=\frac{I}{k} \frac{a D}{\left(1-e^{-a D}\right)} .
$$

Again, $M=I / K$ is the thin sample calibration equation, so the remaining part of the equation can be considered a correction factor:

$$
C=\frac{a D}{\left(1-e^{-a D}\right)}
$$

If we are using the sample as a callbration standard, we can rearrange the equation to

$$
\mathbf{k}=\frac{I}{\mathrm{M}} \mathrm{C} \text {. }
$$

For the thick standards, $e^{-a D}=0$, and the equation reduces to

$$
\mathbf{k}=\frac{\mathbf{I} \mathbf{a}}{\mathrm{w}} \text {. }
$$

It should be mentioned that the units of $\mathrm{w}$ are a bit unusual. They are micrograms of element per $\mathrm{mg} / \mathrm{cm}^{2}$ of sample. The amount is total micrograms per unit thickness, and includes the area of the sample. For instance, a sample with an area of $2 \mathrm{~cm}^{2}$ has a value twice that of the same material with an area of $1 \mathrm{~cm}^{2}$. Another way of writing it is

$$
w=\text { (micrograms of element } /
$$$$
\mathrm{mg} \text { of sample) } \times \text { area . }
$$

Thus, for a pure element standard, such as a metal foil, $w=1000 \times$ area.

The values of a are determined from a tabulation such as that of Storm and Israel $^{*}$ combined with the appropriate anrular correction factors described earlier. For a 1 in. diam sample for our system the factors are $C_{1}=1.10$ and $C_{2}=1.17$.

It should be noted that with ows system it is relatively easy to measure effective absorption coefficients of materials such as filter paper as described above. It is difficult, however, to measure the absorption of an $x$ ray by the material producing the $x$ ray.

For example, if we want to use an infinitely thick $T i$ standard, we need the effective absorption coefficient for $T i$ $x$ ray in $T i$. To make the measurement, we would normally measure a Ti sample, then measure the attenuation of the $\mathrm{Ti}$ $x$ rays by a $T i$ foil of known thickness. However, with our system geometry the Ti absorber foil will fluoresce to produce $T i x$ rays. Thus, the number of $T i x$ rays reaching the detector will be larger with the absorber present, and the measurement of the absorption coefficient becomes difficult.

*E. Storm and H. Israel, Nucl, Data Tables, U.S. At. Energy Comm. Sec. A 7, 565 (1970). 


\section{Appendix C}

ESTIMATED COST PER SAM PLE

Table A-1 of Appendix A shows the cost of a radioisotope excited fluores cence analysis systern at $\$ 35,800$. An additional $8 \mathrm{~K}$ of memory is required for this system to stand alone, i.e. operate without the aid of additional computer capability. Inis adcitional memory costs $\$ 6,500$. For efficient operation of such a system, an automatic sample changer should be developed, at a cost of about $\$ 8,000$. This brings the total capital cost of the system to about $\$ 50,000$. Let us calculate a realistic figure for the cost on a per sample basis amortized over a five-year period. This is the useful mean lifetime of scientific equipment in this category of technical capability. In the discussion that follows, we will sketch the kind of developments which might be typical during each of these five years. Then at the end of this section, the actual dollar figures will be presented in tabular form for clarity.

\section{First Year}

The first year is assumed to begin with delivery of the equipment. A full time scientist will be needed to assemble, calibrate and de-bug the system. The figures will also assume that a technician is hired. At the beginning he will learn to run the system so that during the remaining four years the scientist can devote part of his time to other areas.

One of the most time-consuming jobs could be the software development required to obtain meaningful quantitative numbers from the automated system. Naturally the amount of time required depends a great deal on how much software is delivered with the system. For the purposes of discussion, assume that a three month period is required to develop sufficient software to operate the entire system, During the third quarter the entire system is under test - the automation, the computer programming and the calibration. Meaningful data are obtained during this period, but at a rete only $10 \%$ of the eventual capability of the system. Finally, let us assume that during the last quarter of the first year. the system operates at essentially full capacity.

\section{Second Year}

In the second year it will be assumed that the scientist spends half of his time on the system. The technician spends full time with the system and it operates the entire year at $90 \%$ capacity.

\section{Third Year}

At the start of the third year a new
${ }^{109} \mathrm{Cd}$ source is purchased. This is an expense item. Assume that the staff scientist spends only $25 \%$ of his time working with the system. The technician is again assumed to spend full time with the system which operates at $100 \%$ capacity.

\section{Fourth Year}

Let us assume that the staff scientist must write a major report on the system this year and that the amount of his time spent increases to $40 \%$. Also assume that because of non-routine data which he 
must obtain using the system that it drops to $95 \%$ of full sapacity. In addition, assume that an addillonal secretary was hired partly to help summarize the growing volume of data generated by the system and partly in order to type the major report.

\section{Fifth Year}

At the start of the fifth year both a new ${ }^{109} \mathrm{Cd}$ and a new ${ }^{55} \mathrm{Fe}$ source are needed. These are expense items which total $\$ 5000$. Assume the staff scientist spends only $10 \%$ of his time, the technician spends full time, and the system operates at $100 \%$ capacity.

\section{Capacity of the System}

Assume the following conditions: a $450-\sec { }^{109} \mathrm{Cd}$ fluorescence using a $30 \mathrm{mCi}$ source; the system operates at $40 \%$ deas time, therefore, the total elapsed real time is $12 \mathrm{~min}$. Also, assume that data transfer, manipulation, output and sample changing require an addltional $3 \mathrm{~min}$. Therefore, the total elapsed time for a single sample analysis is $15 \mathrm{~min}$. Assume a $75 \%$ throughput during the normal 40-hr work week, and $100 \%$ throughput during the remainder of the week, or $128 \mathrm{hr}$. This gives

$$
\begin{aligned}
30 \mathrm{hr} \times 4 / \mathrm{hr} & =120 \\
+128 \mathrm{hr} \times 4 / \mathrm{hr} & =\frac{512}{632} \text { samples/week. } \\
\text { or } &
\end{aligned}
$$

This corresponds to 32,864 sample/yr. With about $2.5 \%$ down time devoted to maintenance this leaves 32,000 samples analyzed per year. Let this then be that number of samples that corresponds to a $100 \%$ throughput figure.

\section{Cost per Sample}

Table $C-1$ summarizes the cost per sample amortized over a 5 yr period

\begin{tabular}{|c|c|c|c|c|c|c|}
\hline & & & & & & $\begin{array}{l}5 \mathrm{yr} . \\
\text { totals }\end{array}$ \\
\hline Capital equipment & $\$ 10,000$ & $\$ 10,000$ & $\$ 10,000$ & $\$ 10,000$ & $\$ 10,000$ & $\$ 50,000$ \\
\hline New sources & & & 4,000 & & 5,000 & 9,000 \\
\hline Scientigt salary (\%t) ${ }^{a}$ & $15,000(100)$ & $7,900(50)$ & $4,150(25)$ & $7,000(40)$ & $1,830(10)$ & 35,880 \\
\hline Technician ${ }^{b}$ & 8,000 & 9,000 & 10,000 & 11,000 & 12,000 & 50,000 \\
\hline Overhead $^{c}$ & 23,000 & 16,900 & 14.150 & 24,000 & 20,330 & 98,380 \\
\hline Totals & $\$ 56,00 ?$ & $\$ 43,800$ & $\$ 42,300$ & $\$ 52,000$ & $\$ 49,160$ & $\$ 243,260$ \\
\hline No. Samples & 8,800 & 28,800 & 32,000 & 30,400 & 32,000 & 132,000 \\
\hline \multirow[t]{2}{*}{$\begin{array}{l}\% \text { Handled } / y \mathbf{r} \\
(32,000=100 \%)\end{array}$} & $(27.5)$ & (90) & $\{100\}$ & $(95)$ & $(100)$ & $(82.5)$ \\
\hline & & & & & & Average \\
\hline Cost/Samplè & $\$ 6.36$ & $\$ 1.52$ & $\$ 1,32$ & $\$ 1.71$ & $\$ 1.54$ & $\$ 1.84$ \\
\hline
\end{tabular}
incorporating the assumptions made above.

Table C-1, Cost per sample amortized over 5 yr.

\footnotetext{
Assume a 5\% raise/yr. The (\% time) corresponds to the \% of his time spent on XRFA.

${ }^{b}$ Assume he te ore of those rar, finds, therefore his raises are $12 \frac{1}{3} \%, 11.0 \%, 10 \%$, and $9 \%$ respectively for years $2,3,4$, and 5 .

c Assume the overhead for thr. Ist through $35 \mathrm{~d}$ yearg are equal to the sum of the scientist's and techniclan's salary. For the \&th and 5 th year include the cost of an additlonal secretary at $\$ 6,000$ and $\$ 6,500$ respectively.
} 
These tabulated costs depend directly on the assumptions of course. In order to see how the costs change under slightly different assumptions consider the following. Assume that the time required for fluorescence and complete sample analysis is increased to $30 \mathrm{~min}$. Also, let us assume that we wish to examine each and every sample with two exciters, both the ${ }^{55} \mathrm{Fe}$ and the ${ }^{109} \mathrm{Cd}$. This means that the number of samples corresponding to $100 \%$ throughput becomes one quarter as much, or $8000 / \mathrm{yr}$. Then the cost per sample becomes $\$ 25.45$, $\$ 6.08, \$ 5.28$, $\$ 6.84$, and $\$ 6.12$ for the first tinrough the fifth year respectively, and $\$ 7.36 /$ sample averaged over the entire $5 \mathrm{yr}$ period. The total number of samples handled under these new assumptions over the entire period would be 33,000 .
The importance of automating such a. system must not be overlooked. As was seen in the section which discussed the capacity of the syste $n$, automation can increase the sample handling capabilities by a factor of as much as 5 . Without such automation, the cost will go from $\$ 1.84$ to almost $\$ 10.00$ per sample assuming a $15 \mathrm{~min}$ total analysis time and only a $40 \mathrm{hr}$ week. Assuming a fuorescence with two sources at $30 \mathrm{~min} /$ sample/fluorescer during only a $40 \mathrm{hr}$ week will again raise the cost from $\$ 7.36$ to about $\$ 35.00$ per sample. Therefore the cost/sample strongly depends on the total counting time per sample and whether or not a system is automated. Assumptions about the overhead costs effect the cost/sample by small percentages, while the lack of automation affects these same costs by large factors. 